\title{
PAPEL PATOGENÉTICO DO ESTRESSE NA LESÃO DO MIOCÁRDIO INDUZIDA EXPERIMENTALMENTE PELO EMPEÇONHAMENTO DE ABELHAS AFRICANIZADAS EM RATOS WISTAR: HISTOMORFOMETRIA DA LESÃO.
}

Dissertação apresentada ao Curso de PósGraduação da Faculdade de Medicina de Ribeirão Preto da Universidade de São Paulo, Área de Concentração Patologia, sub-área Patologia Experimental, como requisito parcial para obtenção do Grau de Mestre.

Orientador: Prof. Dr. Roberto Silva Costa Assessora: Profa. Dra. Marlene Antônia dos Reis

RIBEIRÃO PRETO - SP

1998 
Este trabalho foi realizado no Laboratório de Patologia Renal do Departamento de Patologia da Faculdade de Medicina de Ribeirão Preto da Universidade de São Paulo, e contou com o apoio financeiro da Fundação de Amparo à Pesquisa do Estado de São Paulo (FAPESP - Processos n95/6651-3 e 95/0551-7). 
Aos meus pais, Roberto e Marilda, e irmã, Ana Paula, que sempre me incentivaram e apoiaram, e mostraram uma lição de amor, em todos os momentos da vida: muito obrigada!

Á uma pessoa muito especial, Luciano, pelo companheirismo e dedicação que sempre devotou à mim, obrigada por ter participado da minha vida e me ensinado muitas coisas.

"É preciso amar as pessoas como se não houvesse amanhã, porque se você parar prá pensar, na verdade não há..."

(Renato Russo). 


\section{Agradecimentos}

Agradeço a todos aqueles que acreditaram na realização deste trabalho.

À Prof ${ }^{a}$ Dr $^{a}$ Marlene Antônia dos Reis, pela disponibilidade e boa vontade em auxiliar nas diversas fases do trabalho;

Aos técnicos do Departamento de Genética, pela captura das abelhas;

Aos técnicos da ZEISS do Brasil Alex e Milo, pela orientação no manuseio do analisador de imagens;

Às funcionárias do Biotério: Ivone P Silva e Maria A A Caetano pela ajuda no manuseio dos animais;

À técnica Érika P Delloiagono Gual, pela colaboração técnica;

Ao Júlio César de Matos, pela confecção das fotos;

Aos docentes e funcionários do Departamento de Patologia da Faculdade de Medicina de Ribeirão Preto pelo convívio durante a realização deste trabalho;

À companheira de trabalho Gleicilaine A Sena de Aquino, pelo estímulo e apoio durante a realização deste trabalho;

Enfim, a todos que direta ou indiretamente, me apoiaram, estimularam e acreditaram na conclusão deste trabalho. 


\section{SUMÁRIO}

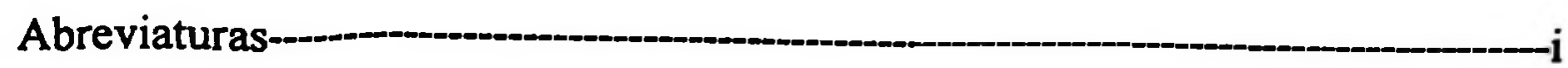

I. INTRODUÇÃO E OBJETIVO-1

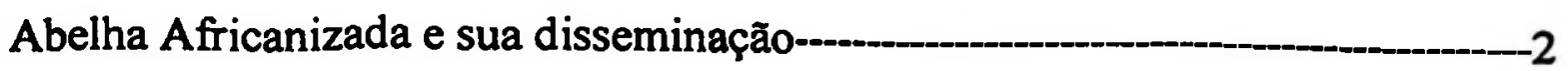

Abelha Africanizada e sua peçonha-_-_-3

Conseqüencias das picadas de abelhas-_- 6

Cardiotoxicidade--11

Objetivo----14

II. MATERIAIS E MÉTODOS-15

Obtenção da peçonha de abelhas africanizadas-16

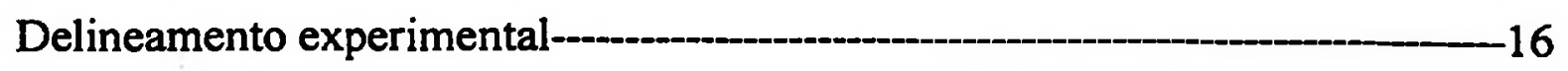

Inoculação da peçonha---17

Sacrificio---17

Estudo morfológico--17

Padronização dos cortes seriados-18

Estudo morfométrico--_-18

Análise estatística--19

III. RESULTADOS-20

Teste das médias acumuladas-_-21

Estudo morfológico---21

Estudo morfométrico-- 22

IV. GRÁFICO, TABELAS E FIGURAS-

V. DISCUSSÃO-39

VI. RESUMO-- 52

VII. SUMMARY 53

VIII. REFERÊNCIAS BIBLIOGRÁFICAS-1- 54

IX. APÊNDICE--67 


\section{ABREVIATURAS}

$\mathrm{AA}=$ Abelha Africanizada

AST $=$ Aspartato aminotransferase

$A T P=$ Trifosfato de adenosina

$\mathrm{CK}=$ Creatinocinase

$\mathrm{CO}=$ Citocromo-oxidase

$\mathrm{DL}_{50}=$ Dose letal média

IRA= Insuficiência renal aguda

$\mathrm{Hb}=$ Hemoglobina

IRA= Insuficiência renal aguda

$\mathrm{LD}=$ Desidrogenase lática

$\mathrm{MAO}=$ Monoamino-oxidase

NTA $=$ Necrose tubular aguda

PAA = Peçonha de Abelha Africanizada

PTAH = Hematoxilina Ácida Tricrômica Fosfotúngstica de Mallory

$\mathrm{SD}=$ Succinato- desidrogenase 
I -INTRODUÇÃO 


\section{Origem das abelhas africanizadas e sua disseminação}

As espécies existentes de abelhas no Continente Americano utilizadas para a produção de cera e mel e utilizadas na polinização, eram principalmente as italianas (Apis mellifera lingustica) e as alemãs (Apis mellifera mellifera) com caracteristicas marcadas pela adaptação ao clima frio, estoque de grandes quantidades de mel e formação de colméias com uma regulação térmica constante. Essas abelhas (meliferas) são da ordem dos himenópteros, que compreende as abelhas, vespas e formigas. Seu comportamento relativamente não agressivo também colaborou com sua manutenção na apicultura (SCHUMACHER \& EGEN, 1995). Em 1956, com o intuito de melhorar a produção de mel e polinização em regiões tropicais, abelhas africanas (Apis mellifera scutellata), provenientes das regiōes oeste e central da África, foram introduzidas no Brasil em Rio Claro-SP. Estas abelhas possuem características de defensividade e agressividade marcantes. Um escape acidental de 26 abelhas rainhas e suas respectivas colméias, levou à hibridização destas com as abelhas já existentes, originando uma nova raça chamada de "abelha africanizada" (AA), com hábitos e comportamento diversos das conhecidas, porém não chegando a ser considerada uma nova espécie (LELLO, 1966; KERR, 1967; GONÇALVES, 1974; MICHENER, 1975; TAYLOR JR, 1977; WINSTON, 1992; DINIZ FILHO \& MALASPINA, 1995; SCHUMACHER \& EGEN, 1995)

A nova raça de abelhas herdou a agresssividade de sua ancestral africana, além de altas taxas de reprodução e crescimento de colônias. Essas caracteristicas associadas à sua habilidade de vôo em longas distâncias, contribuiu para sua rápida disseminação pelo continente, dirigindo-se principalmente para o norte do país, movendo-se de 300 a $500 \mathrm{Km} /$ ano (COLLINS et al, 1982; KERR, DEL RIO \& BARRIONUEVO, 1982; TAYLOR, 1977). O fato da abelha africana ser mais 
agressiva que a européia deve ser consequente à uma herança poligênica com múltiplos alelos presente na subespécie africana (WINSTON, 1992).

Em 1990, as AA cruzaram a fronteira mexicana e chegaram ao território dos EUA. Penetraram no Texas próximo à Brownsville em 1992 e Arizona em 1993 (MUÑOZ-ARIZPE et al, 1992; SCHUMACHER \& EGEN, 1995). Ocupam uma área de 20 milhões de $\mathrm{Km}^{2}$, incluindo grande parte da América do Sul e praticamente toda a América Central (CAMAZINE \& MORSE, 1988; ELGART, 1990, McKENNA, 1992). A expectativa é de que continuem movendo-se para o norte, embora não se adaptem bem ao clima frio (REISMAN, 1994).

Apesar de seu comportamento agressivo, as AA apresentam muitas vantagens em termos de apicultura como maior polinização e produção de cera $e$ mel, chegando a produzir de 1,25 a 2 vezes mais a quantidade de mel por colônia do que as abelhas italianas sob as mesmas condições (GONÇALVES, 1975). Porém sua agressividade leva à ataques maciços, causando os acidentes por múltiplas picadas de abelhas (BRANDEBURGO, 1990; NELSON et al, 1990; SCHUMACHER et al; 1990; REISMAN, 1994).

\section{Abelha Africanizada e sua Peçonha}

De um modo geral, a peçonha de abelhas é bastante estudada. No Brasil, o interesse pelo conhecimento da peçonha das abelhas e seus efeitos foi aumentado depois da aparição da AA em 1956 (LELLO, 1966; KERR, 1967; TAYLOR, 1986; WINSTON, 1992; SCHUMACHER \& EGEN, 1995). Estudos efetuados em sua peçonha, porém, não revelaram diferenças com relação às abelhas italianas. Os componentes mais encontrados da Peçonha de Abelhas Africanizadas (PAA) melitina e fosfolipase A - aparecem em concentraçōes similares tanto nas AA quanto nas abelhas européias, apenas o saco que contém a peçonha parece ser um pouco menor nas AA, porém a letalidade de ambas as peçonhas em ratos mostrouse semelhante, com isso conclui-se que o principal risco para as vítimas das AA é a 
multiplicidade das picadas (MELLO, 1970, SCHIMIDT, 1995; SCHUMACHER \& EGEN, 1995).

Sabe-se que a PAA é constituida por $88 \%$ de água e $12 \%$ de substâncias orgânicas, formando uma mistura complexa com atividade farmacológica variada. A classificação dos constituintes da PAA é aplicada à outros himenópteros também assim como a peçonha das cobras (HABERMANN, 1972). Dentre essas substâncias orgânicas encontramos:

1- Aminas biogênicas (baixo peso molecular) como: histamina, dopamina, noradrenalina, adrenalina, serotonina e aminoácidos livres, sendo a histamina predominante, com uma concentração de 0,1 a 1,5\%. A dopamina e a noradrenalina foram identificadas como constituintes da PAA "in vivo". Os efeitos das aminas biogênicas são obscurecidos pelos grupos de componentes com alto peso molecular (HABERMANN, 1972).

2- Enzimas: hialuronidase e fosfolipases A e B. A hialuronidase atua hidrolisando o ácido hialurônico, facilitando a difusão da peçonha. Tanto a hialuronidase quanto a fosfolipase são importantes alérgenos, sendo provavelmente os antígenos envolvidos nas reações de hipersensibilidade às picadas de abelhas. A fosfolipase apresenta uma ação hemolítica indireta pela sua capacidade de liberar substâncias como a lisolecitina. A melitina libera lecitina dos glóbulos vermelhos e a fosfolipase A atua sobre a lecitina, quebrando seus ácidos graxos não saturados e transformando-a em lisolecitina (HABERMANN, 1972, MELLO, 1972; GAULDIE et al, 1976; KING et al, 1976). A fosfolipase $A_{2}$ afeta também a respiração tissular, inibindo as desidrogenases e inativa a tromboplastina, evitando a coagulação do sangue. Libera também prostaglandinas que alteram a permeabilidade vascular e tomam parte na reação anafilática, na patogênese da inflamação, em certos tipos de alergia e na sintomatologia do choque (MELLO, 1972). A fosfolipase $A_{2}$ contida no veneno de abelha é composta por um único polipeptideo de cadeia simples. Recentemente foi demonstrado que as fosfolipases de cadeias simples extraídas de 
várias peçonhas de animais possuem receptores específicos no cérebro e outros tecidos. Nos receptores detectados foi encontrado o tipo $n$, que possui grande afinidade pela fosfolipase $A_{2}$ contida no veneno de abelha (GANDOLFO et al, 1996). Isso implicaria na neurotoxicidade da fosfolipase.

3- Polipeptídeos (alto peso molecular): a melitina representa $50 \%$ do peso seco da PAA e é a principal responsável pela ação tóxica da mesma. Ela apresenta atividade citolítica inespecífica. A melitina possui uma estrutura semelhante a surfactante e é capaz de diminuir a tensão superficial entre o ar e as soluçð̃es salinas num grau comparável às hemolisinas lisolecitina ou digitonina, por isso acredita-se que a melitina aumenta a permeabilidade de eritrócitos e outras células, até mesmo dissolvendo a membrana como um detergente. A atividade exercida pela melitina sobre as superficies celulares deve-se à sua estrutura molecular composta por vários aminoácidos. A formação de micelas, diminuição da tensão superficial e hemólise podem ser manifestações da estrutura primária da melitina. Ela causa lise direta de hemácias, leucócitos, plaquetas, mastócitos e células musculares esqueléticas, inibe a potência tromboplástica dos preparados teciduais, paralisa a fosforilação oxidativa mitocondrial, despolimeriza a fibra cardíaca ou esquelética, produz dor "in vivo" e bloqueia a transmissão neuro-muscular (HABERMANN, 1972, VERNON \& BELL, 1992; FLETCHER \& JIANG, 1993, OKAMOTO et al, 1995). A melitina ataca também as sinapses neromusculares e ganglionares causando paralisação respiratória, é responsável, em grande parte, pela dor e inflamação, inibe a atividade da anticolinesterase e coagula o fibrinogênio. É o componente mais termoestável do veneno: aquecimento a $100^{\circ} \mathrm{C}$ por uma hora não reduz sua ação (MELLO, 1972). A apamina, que é o fator neurotóxico da peçonha, apresenta interação com a medula espinhal. O peptídeo degranulador de mastócitos é responsável pela liberação de histamina e também mostra-se como um fator préinflamatório potente. A minemina é um fator letárgico para larvas de Drosophila. 
Também são encontradas as substâncias inibidoras de proteases (HABERMANN, 1972, McKENNA, 1992).

4- Outras substâncias como os hidratos de carbono e uma substância volátil, a isoamiloacetato (HABERMANN, 1972).

\section{Conseqüências das picadas de abelhas}

As picadas de abelhas induzem ao aparecimento de quadro clínico muito diversificado, que pode variar desde um pequeno eritema no local da picada até uma insuficiência renal com evolução fatal. Essa variedade de manifestações depende de fatores individuais, como a presença ou não de hipersensibilidade à PAA e o estado geral do paciente, e de fatores inerentes ao acidente, como o número de picadas, local atingido e rapidez no atendimento médico, (RUBENSTEIN, 1982; LICHTENSEN \& GOLDEN, 1983; MENDES et al, 1990; ELGART, 1990).

$\mathrm{O}$ acidente mais frequente se caracteriza por poucas picadas em indivíduos não sensibilizados a um ou mais componentes da PAA, apresentando apenas reação inflamatória local, com pápulas eritematosas, calor e dor que, na maioria das vezes, é solucionada sem participação médica (MENDES et al, 1990).

Uma outra forma de apresentação dos acidentes por picada de abelha caracteriza-se pela sensibilidade do indivíduo a um ou mais componentes da PAA. O quadro pode ser desencadeado por apenas uma picada, seguindo-se uma reação de hipersensibilidade do tipo I, destruição dos mastócitos provavelmente mediada pela IgE, produzindo um quadro de choque anafilático, que pode ser fatal. É ocorrência grave e que necessita de intervenção imediata e segura do médico. Este tipo de reação de hipersensibilidade é o responsável pela maioria dos acidentes fatais descritos na literatura (SCHENKEN, TAMISIEA \& WINTER, 1953; PEARLMAN, 1955; MARSHALL, 1957; PARRISH, 1963; O'CONNOR et al, 1964; ORDMAN, 1969; BARNARD, 1973; 
NAGARATNAM, HUSODO \& JAMES, 1988; COHEN, 1989; FREYE \& ERLICH, 1989; MENDES et al; 1990). É descrito que a peçonha tem propriedades farmacológicas para liberação de mediadores, como por exemplo, o peptídeo degranulador de mastócitos, por mecanismos não imunes, além da fosfolipase A e da melitina (ROTHSCHILD, 1966). A hipotensão é a manifestação clínica mais comum da anafilaxia, sendo a vasodilatação sistêmica e a saída de plasma devido à contração microvascular, implicadas na patofisiologia da hipotensão vista na anafilaxia. Adicionalmente, a hipoxemia, acidose e 0 aumento da pressão intratorácica que se segue de severo broncoespasmo, contribuem para a falência cardiovascular (RAPER \& FISCHER, 1988). O coração de humanos e cobaias, possuem mastócitos que liberam histamina em reações imunológicas e farmacológicas. A reação anafilática em cobaias resulta em liberação de histamina, leucotrienos, prostaglandinas e tromboxane. $\mathrm{O}$ coração humano contém receptores $\mathrm{H}_{1}$ e $\mathrm{H}_{2}$ que, quando estimulados "in vitro", levam a uma taquicardia inicial e aumento da contratilidade, seguida de depressão miocárdica. A histamina é um potente vasoconstrictor coronariano em pacientes com doenças coronarianas (RAPER \& FISCHER, 1988).

Apesar da gravidade desta emergência médica, a conduta a ser seguida coincide com a tomada em todos os casos de hipersensibilidade imediata, com aplicação simultânea de drogas. Essa aplicação é feita na seguinte ordem: a) drogas antihistamínicas como "Fenergan", "Benadril", etc., podendo ser aplicada sob a forma de cremes a $20 \%$, ingeridas como tabletes e nos casos mais graves aplicadas por injeção intramuscular; 2) doses de 0,3 a 0,6 ml de adrenalina a 1:1000 pela via muscular, tomando-se o cuidado de não aplicar em pessoas hipertensas e 3) 10 $\mathrm{cm}^{3}$ de gluconato de cálcio a 10\% por via venosa (MELLO, 1972; MENDES et al, 1990). 
Outra forma de apresentação dos acidentes por picada de abelha caracteriza-se pela inoculação de grande quantidade de peçonha, devido a múltiplas picadas, em geral centenas delas. Nesses casos, manifestam-se vários sinais e sintomas decorrentes da ação das diversas frações da PAA, que agora se encontram em concentrações suficientes para que seus efeitos tóxicos possam ser percebidos. Este tipo de acidente é pouco frequente e, por isso, tem sido pouco relatado na literatura médica (MURRAY, 1964; LEVINE, 1976; BOUSQUET, HUCHARD \& MICHEL, 1984; SAKHUJA et al, 1988; BARSS, 1989; AZEVEDO-MARQUES et al, 1990; MENDES et al, 1990; SERT, TETIKER \& PAYDAS, 1993; FRANÇA et al, 1994).

As reações mais freqüentes encontradas em vítimas de múltiplas picadas de AA, fatais ou não, envolvem quadros de hemólise, rabdomiólise, neurotoxicidade, nefrotoxicidade e cardiotoxicidade (REISMAN \& LIVINGSTON, 1989), as quais serão relatadas a seguir.

Os relatos de hemólise intravascular maciça são freqüentes nesse tipo de acidente (BOUSQUET, HUCHARD \& MICHEL, 1984; AZEVEDO-MARQUES et al, 1990; MENDES et al, 1990; FRANÇA et al 1994), esse efeito deve-se a propriedade hemolisante da melitina e à lise indireta causada pela fosfolipase-A (HABERMANN, 1972).

Num estudo feito por FERREIRA (1990) em ratos Wistar inoculados pelas vias intramuscular, intraperitoneal, subcutânea e intravenosa com PAA na dose de $1,5 \mu \mathrm{l} / 100 \mathrm{~g}$, foram observadas alterações sistêmicas apenas no grupo inoculado pela via intravenosa, similares aos achados em acidentes com humanos. Após inoculação da PAA, observou-se intensa hemólise no sangue coletado em tubos de ensaio para exames laboratoriais, minutos após a inoculação, bem como eliminação de urina hemoglobinúrica pelos animais, confirmando a ação hemolisante do veneno. 
Nos acidentes causados por múltiplas picadas de abelhas freqüentemente são descritas a rabdomiólise, liberando a mioglobina que seria tóxica aos túbulos renais, associada à insuficiência renal e/ou necrose tubular aguda (VENTERS et al,1961; MURRAY, 1964; SERT, TETIKER \& PAYDAS, 1993). A rabdomiólise, às vezes não está presente, mas o paciente evolui para falência renal, daí ter sido sugerida uma atividade tóxica direta da peçonha (NACE et al, 1992; BECCARI et al, 1993).

No modelo experimental feito com ratos Wistar (FERREIRA, 1990), os grupos inoculados com PAA pelas vias intramuscular, intraperitoneal e subcutânea apresentaram extensa rabdomionecrose e rabdomiólise local, porém o grupo inoculado pela via intravenosa apresentou lesão na musculatura esquelética à distância ao ser analisado ao microscópio de luz. Neste modelo foi demonstrada também a elevação sérica das enzimas AST e a CKMb, sendo indicativa de lesão muscular esquelética (EBASHI, 1959; GABOW, KAEHNY \& KELLEHER, 1982, AZEVEDO-MARQUES, FERREIRA \& COSTA, 1992). Recentemente (OWNBY et al, 1997) demonstrou-se que ambas, melitina e fosfolipase $A_{2}$, são capazes de provocar necrose em músculo esquelético, e que os dois componentes da PAA, atuam sinergicamente para induzir um efeito miotóxico maior e mais rapidamente.

A alteração renal em vítimas de múltiplas picadas de himenópteros, fatais ou não, tem sido observada há anos, apesar de ser um fenômeno incomum (ABUELO, 1990). SERT, TETIKER \& PAYDAS (1993), descrevem um caso de um homem de 68 anos que foi picado por milhares de abelhas e desenvolveu rabdomiólise seguida de IRA. BARSS (1989) também descreve o caso de seis pessoas picadas por milhares de vespas, onde quatro delas desenvolveram IRA. Como já foi dito anteriormente, a rabdomiólise pode estar presente ou não no desenvolvimento da IRA e NTA. FEINFELD et al (1992), desenvolveram um estudo com o objetivo de medir os niveis de mioglobina no sangue e urina de pacientes que desenvolveram rabdomiólise, para determinar qual o nivel crítico 
desta proteína associada com o desenvolvimento de IRA. Todos os oito pacientes tiveram níveis de CK elevados compatíveis com o critério admitido para ocorrência de rabdomiólise (GABOW, KAEHNY \& KELLEHER, 1982), e também apresentaram nível de mioglobina elevado. Embora quatro pacientes tenham desenvolvido IRA, apenas dois apresentaram nível de CK muito acima do normal, enquanto os quatro apresentaram nível de mioglobina acima de 1.000 $\mathrm{ng} / \mathrm{ml}$.

No estudo de FERREIRA (1990), utilizando dose alta de $1,5 \mu 1 / 100 \mathrm{~g}$, a lesão renal foi observada apenas no grupo de animais inoculados com PAA pela via intravenosa, com os animais sobrevivendo de um a treze minutos. A principal alteração renal encontrada foi a necrose das células do epitélio tubular na medular externa, sendo a gravidade da lesão diretamente proporcional ao tempo de sobrevida dos animais.

Com a intenção de investigar a fisiopatogênese da NTA neste modelo, foi inoculada PAA na dose de $0,4 \mu \mathrm{l} / 100 \mathrm{~g}$ pela via intravenosa, em ratas Wistar (REIS, 1995). Neste estudo foram observadas alterações funcionais, morfológicas e renais. Os animais apresentaram insuficiência renal aguda por diminuição da taxa de filtração glomerular (TFG) e aumento da creatinina plasmática. Apresentaram ainda aumento da fração de excreção de $\mathrm{Na}^{+}$e de $\mathrm{K}^{+}$, sugerindo alterações nas porções proximais do néfron. O estudo morfológico mostrou NTA à microscopia de luz, principalmente ao nivel do córtex e medular externa, com necrose isolada de células ou pequenos grupos e formação de cilindros, caracterizando a NTA do tipo isquêmica. $\mathrm{O}$ estudo imuno-histoquímico revelou a presença de mioglobina $\mathrm{e}$ actina muscular nos cilindros tubulares, sugerindo a participação destas substâncias na agressão de células tubulares. A microscopia eletrônica mostrou alterações principalmente nos segmentos do túbulo proximal e ramo ascendente da alça de Henle. Estas alterações foram caracterizadas por degeneração hidrópica, com apagamento das interdigitações basolaterais e retificação das 
microvilosidades. A IRA encontrada foi devido à NTA, a qual deve ser provavelmente multifatorial, destacando as alterações hemodinâmicas, secundárias à cardiotoxicidade e vasodilatação sistêmica provocadas pela peçonha; a mioglobinúria e a ação direta da peçonha nas células tubulares (REIS, 1995).

Algumas alterações neurológicas são observadas em acidentes por múltiplas picadas de abelha, como descreve MENDES et al (1990), como o estado agitado dos pacientes. Os peptídeos da família melitina apresentam comprovada ação inibidora da acetilcolinesterase, o que levaria a uma prolongada excitação sináptica. Tal excitação ocorre também por ação da fração apamina por outro mecanismo ainda não determinado (MENDES et al, 1990). A apamina é considerada um dos peptídeos mais tóxicos para os mamíferos, ela é capaz de transpor a barreira sangüínea/cerebral e agir sobre o sistema nervoso central (LABBÉ-JULLIÉ et al, 1991). No modelo desenvolvido por FERREIRA (1990), a neurotoxicidade da PAA foi observada clinicamente através de hiperextensão, paralisia e crises convulsivas.

\section{Cardiotoxicidade}

O envolvimento do sistema cardiovascular após picadas de himenópteros, incluindo as abelhas, são relatados em alguns trabalhos. As vítimas apresentaram arritmias cardíacas, taquicardias e aumento ou diminuição da pressão. Essas alterações são relatadas como efeito indireto à anafilaxia. Alterações eletrocardiográficas e casos de infarto do miocárdio foram bem relatados em vítimas humanas que desenvolveram hipersensibilidade após picadas de vespas (LEVINE, 1976; NAGARATNAM, HUSODO \& JAMES, 1988; FREYE \& ERLICH, 1989).

Com a intenção de investigar a cardiotoxicidade ocasionada pelo empeçonhamento por PAA, foi desenvolvido um modelo por FERREIRA (1990), onde a PAA foi inoculada pela via intravenosa em ratos Wistar. Primeiro foi 
avaliada a função cardíaca através de um eletrocardiograma realizado após a inoculação de 0,4 $\mu \mathrm{l}$ da PAA. Observaram-se alterações, tais como aumento do comprimento do complexo QRS e da amplitude da onda $T$, acompanhados do aumento da frequência cardiaca (BESTETTI et al, 1991). Foi avaliada também a noradrenalina tecidual cardíaca. Inoculando-se $1,5 \mu \mathrm{l}$ da PAA pela vias IM,IP, SC e IV, foi observada a diminuição de noradrenalina tecidual, na via IV, sugerindo liberação da mesma pelo tecido (FERREIRA et al, 1993/94). Estes dados, tomados em conjunto, sugerem que a morte destes animais pode ser devida, às alterações funcionais do músculo cardíaco induzidas pela liberação de noradrenalina.

Para melhor avaliação da lesão cardiaca, a PAA foi injetada pela via intravenosa na dose de $0,8 \mu \mathrm{l} / 100 \mathrm{~g}$ de peso ( $\mathrm{DL}_{50}$ ). Os animais foram avaliados 1 , 4 e $24 \mathrm{~h}$ após a inoculação da peçonha. A medida dos níveis séricos de enzimas mostrou aumento significativo nos níveis de CK, LD E AST nos grupos experimentais, 1, 4 e $24 \mathrm{~h}$ após a inoculação da PAA. Os níveis de Hb mostraramse aumentados somente 1 e 4 h após a inoculação, voltando ao normal no grupo de 24h (FERREIRA, 1993; FERREIRA et al, 1995).

Os dados histoquimicos obtidos no ápice do coração mostraram que as lesões variam de intensidade de acordo com o tempo entre o empeçonhamento e a morte. A inativação total da ATP-A, SD, CO e MAO foi observada no centro da lesão enquanto que uma inativação parcial foi observada na periferia das lesões (FERREIRA, 1993; FERREIRA et al, 1995).

Ao microscópio de luz, $80 \%$ dos animais mostraram necrose coagulativa das fibras do miocárdio, às vezes envolvendo pequenos focos, e outras formando áreas extensas semelhantes à infarto do miocárdio na parede do ventrículo esquerdo. Um infiltrado inflamatório intenso foi observado nas referidas áreas, com predominância de células mononucleares (FERREIRA, 1993; FERREIRA et al, 1995). As lesões apresentaram-se com maior frequência nos ápices cardiacos e foram classificadas segundo o critério de BAROLDI (1975). 
É possivel que a mionecrose observada nos animais seja mais um exemplo de lesão catecolaminogênica do coração (SZAKACS \& MEHLMAN, 1960; OLIVEIRA et al, 1986; GUERON \& YARON, 1970). A atividade aumentada da MAO ao redor das lesões sugere uma adaptação das células do músculo cardiaco adjacentes à lesão para facilitar o metabolismo rápido das catecolaminas liberadas no sítio da lesão (FERREIRA et al, 1995). No sentido de uma lesão catecolaminogênica temos várias evidências que colaboram para a suspeita da mesma. Seguramente os animais inoculados com PAA estavam submetidos à situações de estresse no sentido amplo como: orgânico, hemodinâmico e vital, com hiperestimulação do sistema nervoso simpático. As lesões encontradas foram muito sugestivas de lesão por catecolaminas, conforme os critérios de BAROLDI (1975). Já há algum tempo admite-se que o estresse aumenta a toxidade das peçonhas (STAHNKE, 1965). Em reações de defesa, como a provocada pelo estresse, o hipotálamo é estimulado, desencadeando uma resposta do sistema nervoso simpático com descarga de adrenalina (KORNER, 1979). Isso desencadeia uma reação com aumento da pressão sangüinea, taquicardia com conseqüente aumento do débito cardíaco, sendo que esta reação pode ser potencializada pela adrenalina existente na peçonha (HABERMANN, 1972). Outro dado a favor da lesão catecolaminogênica é que no trabalho de FERREIRA et al (1993/94), as dosagens teciduais de noradrenalina cardíaca mostraram-se baixas, evidenciando liberação da mesma.

De acordo com esses dados, a hipótese de uma potencialização da lesão provocada pelo empeçonhamento com PAA pelo estresse, foi levantada. 


\section{Objetivo}

O objetivo do presente trabalho é avaliar a participação do estresse na potencialização da lesão cardíaca induzida experimentalmente pela inoculação intravenosa da peçonha de abelhas africanizadas (PAA), em dose subletal, em ratos Wistar, através da análise histomorfométrica da lesão. 
II- MATERIAIS E MÉTODOS 


\section{Obtenção da peçonha de abelhas africanizadas}

As abelhas africanizadas foram capturadas de diferentes colméias do apiário do Departamento de Genética da FMRP-USP. Uma vez capturadas, as abelhas foram colocadas no freezer onde permaneceram cerca de uma hora, periodo necessário para que entrem em estado de dormência. Em seguida, destinam-se à extração do veneno "in natura". A extração manual da peçonha é realizada por compressão da glândula de veneno com auxilio de uma pinça sob lupa (MELLO, 1970). A peçonha é armazenada em uma micropipeta e em seguida diluida em solução salina 1:500. As doses inoculadas foram de $0,6 \mu \mathrm{l} / 100 \mathrm{~g}$ e $0,8 \mu \mathrm{l} / 100 \mathrm{~g}$ de peso corporal.

\section{Delineamento Experimental}

Foram utilizados 48 ratos albinos, machos, da linhagem Wistar, com peso em torno de $100 \mathrm{~g}$ (variando de 90 a $120 \mathrm{~g}$ ), alimentados com dieta comercial e água "ad libitum". Estes animais foram divididos em 6 grupos: Controle Salina $(C S)=(n=6)$, Estresse Salina $(E S)=(n=6)$, Peçonha 0,6 $(P 0,6)=(n=6)$, Peçonha $0,8(P 0,8)=(n=18)$, Estresse Peçonha $0,6(E P 0,6)=(n=6)$ e Estresse Peçonha 0,8 $(E P 0,8)=(n=6)$. Todos os animais foram inoculados pela via intravenosa através da veia lateral da cauda. Os animais do grupos CS e ES foram inoculados com solução salina e dos grupos $\mathrm{P} 0,6, \mathrm{P0}, 8, \mathrm{EP} 0,6$ e EP0,8 foram inoculados com PAA. Os grupos ES, EPO,6 e EP0,8 foram submetidos a 3 horas de estresse por contenção a $4^{\circ} \mathrm{C}$ (RENAUD, 1959; COCHRAN et al, 1982; MANTOR et al, 1989). O estresse de contenção foi obtido pela imobilização dos membros dos animais em uma grade. Em seguida os animais foram colocados dentro da geladeira a $4^{\circ} \mathrm{C}$ por 3 horas, como está demonstrado na fig 1 . 


\section{Inoculação da Peçonha:}

Após o período de ambientação, onde os animais permaneceram $24 \mathrm{~h}$ recebendo ração e água "ad libitum", os mesmos foram identificados e pesados para adequação à dose a ser inoculada. Os animais foram confinados em uma caixa contendo uma lâmpada por aproximadamente um minuto, a fim de promover vasodilatação e assim facilitar o processo de inoculação da peçonha, como demonstra a fig 2. A peçonha foi inoculada pela veia lateral da cauda (via intravenosa) nas dosagens de $0,6 \mu \mathrm{l} / 100 \mathrm{~g}$ e $0,8 \mu \mathrm{l} / 100 \mathrm{~g}$ como está demonstrado na fig 2.

\section{Sacrifício}

Após 24 horas os animais foram anestesiados com éter, foi feita uma incisão em U na cavidade torácica e abdominal dos mesmos, demonstrada na fig 3 , os corações foram retirados, secados em papel de filtro, sendo submetidos a um corte transversal na altura do coxin atrio-ventricular e, em seguida, fixados em uma solução de formalina tamponada a $10 \%$ por $24 \mathrm{~h}$.

\section{Estudo Morfológico}

Os corações foram retirados e secados em papel de filtro, pesados em balança de torção e imersos em solução formalina a $10 \%$ tamponada durante 5 minutos. Estes espécimes foram processados para inclusão em parafina, seccionados em série, com 5 micrômetros de espessura, corados com hematoxilina fosfotúngstica (PTAH) e examinados ao microscópio de luz comum. Os critérios utilizados para caracterizar a lesão da fibra muscular foram os de BAROLDI (1975). 


\section{Padronização dos cortes seriados}

Foi realizado o teste das médias acumuladas no coração dos animais para a determinação do número de cortes a serem submetidos às análises morfológicas e morfométricas (WILLIANS, 1977). O coração foi seccionado inteiramente e sua área do miocárdio foi medida $\mathrm{em} \mathrm{mm}^{2}$. Cada medida obtida foi colocada aleatoriamente em uma lista de dados onde as médias de cada medida somavam-se às outras, obtendo-se no final um valor correspondente à $100 \%$, isto é, a totalidade da área miocárdica medida. A partir deste valor, com uma simples regra de três, as respectivas medidas foram transformadas em porcentagem e estes valores foram dispostos em um gráfico para observação da estabilização da curva com um $\alpha=5 \%$, onde foi encontrado o número ideal de cortes a serem feitos para as devidas análises. As lâminas contendo os cortes seriados estão representadas nas fig 4 e 5 .

\section{Estudo morfométrico}

O estudo morfométrico constou da medida de área do corte histológico como um todo, das áreas das cavidades, do miocárdio e, posteriormente, a medida da área de necrose, calculando-se a proporção das áreas de necrose/não necrose nos animais empeçonhados, submetidos à forma de estresse por contenção e animais empeçonhados não submetidos a estresse, comparativamente aos respectivos animais controles.

As análises morfométricas foram realizadas utilizando-se uma câmera de vídeo acoplada a um microscópio de luz. As imagens obtidas no monitor de vídeo foram conectadas a um sistema analisador de imagens automático KS 300 KONTRON IMAGING SYSTEM, KONTRON ELEKTRONIK, demonstrado na fig 6 , que realizou as medidas das áreas já mencionadas. 


\section{Análise Estatística}

As distribuições dos valores obtidos foram submetidas aos testes de simetria, com a utilização do Coeficiente de assimetria de Pearson. Quando simétricas foram analisadas com testes paramétricos $e$, quando não, por testes não paramétricos. O teste " $t$ " de Student e a prova " $U$ " de Mann-Whitney, foram aplicadas segundo Berquó (1981). As diferenças observadas foram consideradas significativas quando a probabilidade de rejeição da hipótese de nulidade (H0) era menor que $5 \%(p<0,05)$. Os resultados foram expressos em média aritmética, desvio padrão e mediana. 
III- RESULTADOS 


\section{TESTE DAS MÉDIAS ACUMULADAS}

$\mathrm{O}$ teste das médias acumuladas determinou o número de cortes a serem feitos para a devida análise histomorfométrica. O gráfico número 1 mostra a distribuição e estabilização dos cortes e ver que o número encontrado, devido à estabilização da curva, para a representação do coração de rato Wistar com peso em torno de 100 a $120 \mathrm{~g}$, foi de 16 cortes para cada animal. Sendo que, na confecção dos cortes, 60 eram desprezados e 1 era destinado a análise histomorfométrica, até o coração ser completamente seccionado.

\section{ESTUDO MORFOLÓGICO}

\section{Microscopia de luz comum}

A análise histopatológica das seç̧ões transversais do coração dos animais do grupo controle apresentou padrão normal de músculo estriado cardíaco. Nos grupos experimentais submetidos ou não ao estresse, em ambas as doses, a lesão encontrada foi a necrose de coagulação. Segundo os critérios de Baroldi (1975), as alterações histopatológicas encontradas em doenças cardiacas resultando em infarto do miocárdio foram classificadas em (a) necrose coagulativa do infarto, (b) miocitólise coagulativa e (c) miocitólise coliquativa. A porce de animais que apresentaram necrose assim como mortalidade dos mesmos estão relacionadas nas tabelas 1 e 2 , respectivamente. Os resultados mostraram que no grupo P0,6, dos 6 animais inoculados, 2 apresentaram necrose (33,3\%), no grupo P0,8, dos 18 animais inoculados, 5 apresentaram necrose $(27,7 \%)$ no grupo EP0,6, dos 6 animais inoculados, 3 apresentaram necrose (50\%), no grupo EP0,8, dos 6 animais inoculados, 2 apresentaram necrose (33,3\%). As lesões encontradas nos grupos experimentais mostraram-se predominantemente no ápice do ventrículo esquerdo, o lado direito do coração foi preservado. A base ventricular esquerda também exibiu lesão, porém com freqüência menor que o ápice, confirmando os resultados de FERREIRA (1993). A lesão encontrada foi do tipo necrose de fibras 
miocárdicas (coagulativa), acometendo ora focos pequenos, ora grandes áreas do miocárdio ventricular esquerdo, apresentando perda da capacidade tintorial do tecido cardiaco, às vezes com homogeneização citoplasmática e desaparecimento nuclear e acompanhado por infiltrado inflamatório constituído de leucócitos predominantemente mononucleares e poucos leucócitos polimorfonucleares, permeando as áreas de lesão. A porção interna do miocárdio necrótico apresenta alongamento com redução do diâmetro das fibras musculares. Seus núcleos desaparecem subseqüentemente, enquanto o aparato miofibrilar ainda mostra-se visivel com aparente aumento no comprimento dos sarcômeros. Os focos pequenos de necrose mostraram-se com caracteristicas da miocitólise coagulativa de acordo com BAROLDI (1975). As lesð̃es encontradas nos respectivos grupos experimentais estão demonstradas nas figuras 7 a 14.

\section{ESTUDO MORFOMÉTRICO}

Os resultados do estudo morfométrico dos corações de ratos inoculados com salina ou peçonha estão organizados nas tabelas 3 a 7 .

A tabela 3 mostra a distribuição da área total do coração dos animais inoculados com salina ou peçonha, com ou sem estresse, com os seguintes dados: $\mathrm{X}=$ média, $\mathrm{S}=$ desvio padrão, mediana e respectiva análise estatistica.

A tabela 4 mostra a distribuição da área do miocárdio do coração dos animais inoculados com salina ou peçonha, com ou sem estresse, com os seguintes dados: $\mathrm{X}=$ média, $\mathrm{S}=$ desvio padrão, mediana e respectiva análise estatística.

A tabela 5 mostra a distribuição da área das cavidades do coração dos animais inoculados com salina ou peçonha, com ou sem estresse, com os seguintes dados: $X=$ média, $S=$ desvio padrão, mediana e respectiva análise estatística.

A tabela 6 mostra a distribuição da área de necrose dos corações dos animais inoculados com salina ou peçonha, com ou sem estresse, com os seguintes dados: $\mathrm{X}=$ média, $\mathrm{S}=$ desvio padrão, mediana e respectiva análise estatistica. 
A tabela 7 mostra a distribuição da relação área de necrose/área do miocárdio dos corações dos animais inoculados com salina ou peçonha, com ou sem estresse, com os seguintes dados: $X=$ média, $S=$ desvio padrão, mediana $\mathrm{e}$ respectiva análise estatística.

Nas medidas de área total, apenas o grupo controle e o grupo controle com estresse apresentaram uma diferença estatisticamente significante e essa diferença se repete quando compara-se a área de miocárdio. $O$ grupo com a dose de $0,6 \mu \mathrm{l} / 100 \mathrm{~g}$ de peso e o grupo com a dose de $0,8 \mu \mathrm{l} / 100 \mathrm{~g}$ de peso, sem estresse, quando comparados, apresentaram diferença estatisticamente significante, em relação à área de miocárdio. A área das cavidades não apresentou diferença estatisticamente significante em nenhum grupo. Nas áreas de necrose, como suspeitava-se, tanto o grupo com a dose de $0,6 \mu \mathrm{l} / 100 \mathrm{~g}$ de peso de peçonha e submetidos ao estresse quanto o grupo com a dose de $0,8 \mu 1 / 100 \mathrm{~g}$ de peso de peçonha e submetidos ao estresse apresentaram diferença estatisticamente significante quando comparados aos grupos empeçonhados sem estr ssse, e consequentemente sua relação com a área do miocárdio intacto também.

Quando comparamos o grupo inoculado com a dose de $0,6 \mu \mathrm{l} / 100 \mathrm{~g}$ de neso de peçonha e o grupo inoculado com a dose de $0,8 \mu \mathrm{l} / 100 \mathrm{~g}$ de peso de peçonha, ambos submetidos ao estresse, em relação a área de necrose, não encontramos diferença estatisticamente significante, porém quando comparamos o grupo com a dose de $0,6 \mu \mathrm{l} / 100 \mathrm{~g}$ de peso de peçonha e o grupo com a dose de $0,8 \mu \mathrm{l} / 100 \mathrm{~g}$ de peso de peçonha, também em relação a área de necrose, encontramos diferença estatisticamente significante. 
IV - GRÁFICO, TABELAS E FIGURAS 


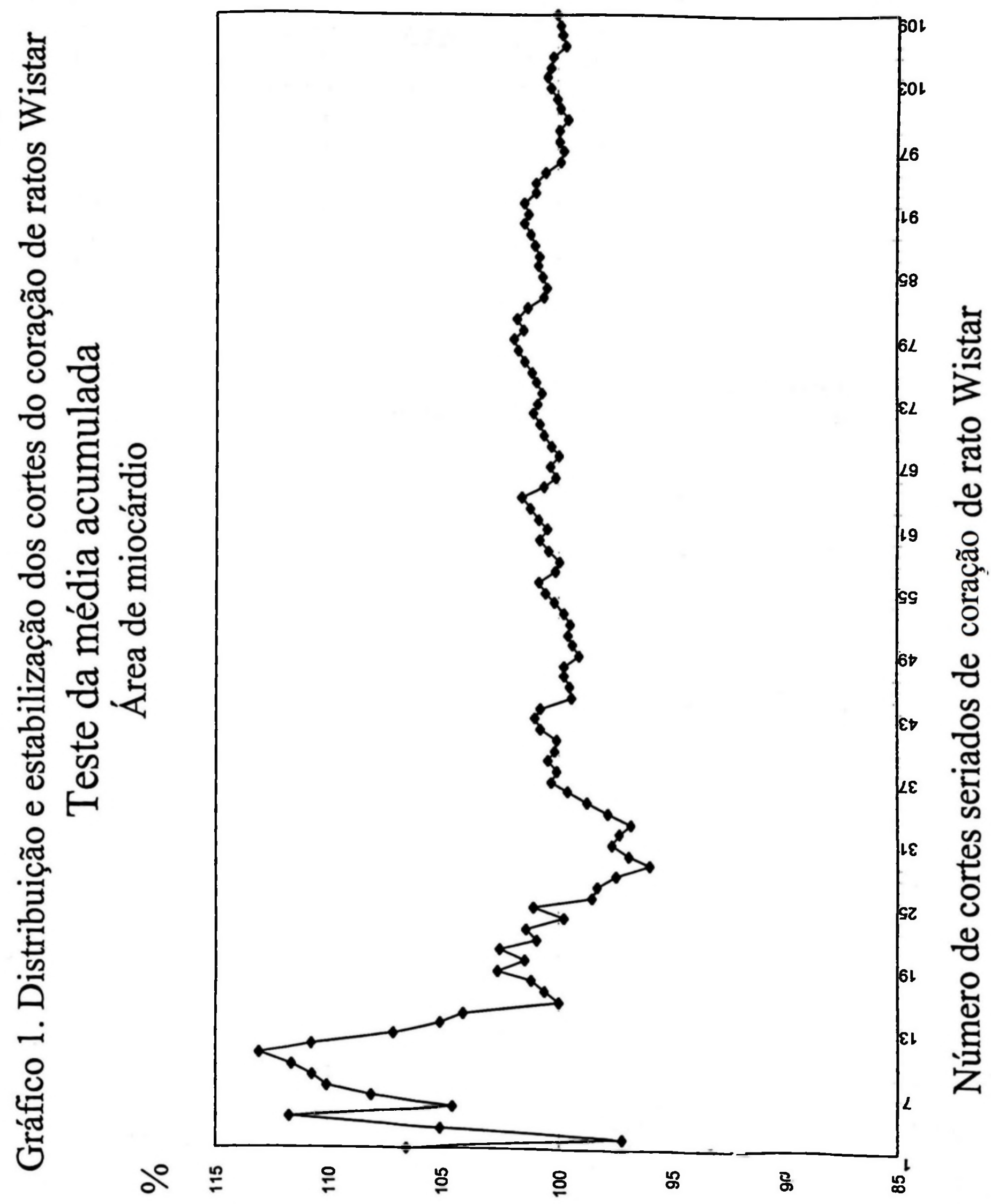


Tabela 1. Distribuição da análise morfológica e porcentagem de $n^{\circ}$ ide animais com necrose do grupos salina e peçonha com e sem estresse.

\begin{tabular}{lcc}
\hline GRUPO & ANIMAIS & ANIMAIS COM \\
CS & ANALISADOS & NECROSE \\
P0,6 & 6 & $0(0 \%)$ \\
P0,8 & 6 & $2(33,3 \%)$ \\
ES & 18 & $5(27,7 \%)$ \\
EP0,6 & 6 & $0(0 \%)$ \\
EPO, & 6 & $3(50 \%)$ \\
TOTAL & 6 & $2(33,3 \%)$ \\
Obs: CS= grupo controle (inoculado com salina), P0,6= grupo peçonha com a \\
dose de $0,6 \mu 1 / 100 \mathrm{~g}, \mathrm{P0}, 8=$ grupo peçonha com a dose de $0,8 \mu \mathrm{l} / 100 \mathrm{~g}, \mathrm{ES}=$ grupo \\
estresse de 3 horas + salina, EP0,6= grupo estresse de 3 horas + peçonha com a \\
dose de $0,6 \mu 1 / 100 \mathrm{~g}$, EP0,8= grupo estresse de 3 horas + peçonha com a dose de \\
0,8 $\mu \mathrm{l} / 100 \mathrm{~g}$.
\end{tabular}

Teste de Fischer

CS X P0,6 p $=0,454$

CS X P0,8 $\quad \mathrm{p}=0,2800$

CS X EP0,6 p $=0,181$

CS X EP0,8 $\quad \mathrm{p}=0,454$

$\mathrm{P} 0,6 \times \mathrm{P} 0,8 \quad \mathrm{p}=1,0$

$\mathrm{P} 0,6 \times$ XP $0,6 \mathrm{p}=1,0$

$\mathrm{P} 0,6 \times \mathrm{EP} 0,8 \mathrm{p}=1,0$

$\mathrm{P} 0,8 \times \mathrm{EP} 0,6 \mathrm{p}=0,361$

$\mathrm{P} 0,8 \times$ EP $0,8 \mathrm{p}=1,0$

$\mathrm{EP} 0,6 \times \mathrm{XP} 0,8 \mathrm{p}=1,0$ 
Tabela 2. Distribuição da mortalidade em ratos Wistar inoculados com peçonha de abelhas africanizadas e salina com e sem estresse

\begin{tabular}{lcc}
\hline GRUPO & ANIMAIS & MORTALIDADE \\
& INOCULADOS & \\
CS & 21 & $1(4,7 \%)$ \\
P0,6 & 20 & $8(40 \%)$ \\
P0,8 & 65 & $44(67,7 \%)$ \\
ES & 20 & $0(0 \%)$ \\
EP0,6 & 38 & $23(60,5 \%)$ \\
EP0,8 & 39 & $31(79,5 \%)$ \\
TOTAL & 203 & 107 \\
\hline
\end{tabular}

Obs: $\quad$ CS $=$ grupo controle (inoculado com salina), $\mathrm{P} 0,6=$ grupo peçonha com a dose de $0,6 \mu \mathrm{l} / 100 \mathrm{~g}, \mathrm{P} 0,8=$ grupo peçonha com a dose de $0,8 \mu \mathrm{l} / 100 \mathrm{~g}, \mathrm{ES}=$ grupo estresse de 3 horas + salina, EP0,6= grupo estresse de 3 horas + peçonha com a dose de $0,6 \mu \mathrm{l} / 100 \mathrm{~g}, \mathrm{EPO}, 8=$ grupo estresse de 3 horas + peçonha com a dose de $0,8 \mu \mathrm{l} / 100 \mathrm{~g}$.

$$
\begin{aligned}
& \text { Prova do } x^{2} \\
& p=0,00001
\end{aligned}
$$

Teste de Fischer
CS X P 0,6
$\mathrm{p}=0,00886$
$\mathrm{CS} \times \mathrm{P} 0,8$
$\mathrm{p}=0,000019$
CS XES
$\mathrm{p}=1,0$
CS X EP0,8
$\mathrm{p}=0,000001$
CS X EP0,6 $\mathrm{p}=0,0000967$
$\mathrm{P} 0,8 \times$ ES $\quad \mathrm{p}=0,000001$
$\mathrm{P} 0,8 \times$ EP0,6 $\mathrm{p}=0,4617$
$\mathrm{P} 0,8 \times$ XP0,8 $\mathrm{p}=0,194$
$\mathrm{ES} \mathrm{XEP0,6} p=0,0000075$
ES X EPO, $8 \quad p=0,0$
EP0,6 X EP0 $, 8 p=0,0691$
$\mathrm{P} 0,6 \times \mathrm{P} 0,8 \quad \mathrm{p}=0,0262$
$\mathrm{P} 0,6 \times$ ES $\quad \mathrm{p}=0,00327$
$\mathrm{P} 0,6 \times$ EP0, $6 \mathrm{p}=0,136$
$\mathrm{P} 0,6 \times$ EP $\quad \mathrm{p}=0,00242$ 
Tabela 3- Distribuição da área total do coração dos animais inoculados com peçonha ou salina, com ou sem estresse

\begin{tabular}{lcccl}
\hline \multicolumn{5}{c}{ ÁREA TOTAL $\left(\mathbf{m m}^{2}\right)$} \\
\hline GRUPO & $\mathbf{X}$ & $\mathbf{s}$ & MEDIANA & SIMETRIA \\
CS & 30,957 & 11,463 & 30,370 & $\bullet$ \\
P0,6 & 35,140 & 11,032 & 38,805 & $\#$ \\
P0,8 & 33,631 & 12,881 & 36,520 & $\bullet$ \\
ES & 34,860 & 6,882 & 36,760 & $\bullet$ \\
EP0,6 & 33,145 & 10,308 & 35,610 & $\bullet$ \\
EP0,8 & 34,305 & 13,347 & 37,675 & $\bullet$ \\
\hline
\end{tabular}

Legenda: Todas as variáveis estão expressas na forma de X(média); S(desvio padrão); \#istribuição assimétrica; - distribuição simétrica; $\alpha=5 \%$.

$\mathrm{CS}=$ grupo controle (inoculado com salina); $\mathrm{P0}, 6=$ grupo peçonha com a dose de $0,6 \mu \mathrm{l} / 100 \mathrm{~g} ; \mathrm{P} 0,8=$ grupo peçonha com a dose de $0,8 \mu \mathrm{l} / 100 \mathrm{~g} ; \mathrm{ES}=$ grupo estresse de 3 horas à $4^{\circ} \mathrm{C}+$ salina; EPO, $6=$ grupo estresse de 3 horas à $4^{\circ} \mathrm{C}+$ peçonha com a dose de $0,6 \mu \mathrm{l} / 100 \mathrm{~g} ; \mathrm{EP} 0,8=$ grupo estresse de 3 horas à $4^{\circ} \mathrm{C}+$ peçonha com a dose de $0,8 \mu \mathrm{l} / 100 \mathrm{~g}$.

$\mathrm{CS} \times \mathrm{ES}$

$\mathrm{PO}, 6 \mathrm{X}$ EP0,6

$\mathrm{P} 0,8 \times \mathrm{EP} 0,8$

$\mathrm{ES} \times \mathrm{EP} 0,6 \times \mathrm{EP} 0,8$

$\mathrm{P} 0,6 \times \mathrm{P} 0,8$

$\mathrm{EP} 0,6 \times \mathrm{EP} 0,8$
Prova "U" de Mann-Whitney

ou " $t$ " de Student ou " $f$ " de anova

$\mathrm{t}=2,76 \quad \mathrm{p}=0,006$

$\mathrm{U}=3,305, \mathrm{p}=0,069$

$\mathrm{t}=0,428 \quad \mathrm{p}=0,672$

$\mathrm{f}=0,642 \mathrm{p}=0,532$

$\mathrm{U}=1,106 \mathrm{p}=0,293$

$\mathrm{t}=0,664 \quad \mathrm{p}=0,514$ 
Tabela 4- Distribuição da área do miocárdio dos animais, inoculados com peçonha ou salina, com ou sem estresse.

\begin{tabular}{lcccl}
\hline \multicolumn{5}{c}{ ÁREA DO MIOCÁRDIO $\left(\mathbf{m m}^{2}\right)$} \\
\hline GRUPO & X & s & MEDIANA & SIMETRIA \\
CS & 22,560 & 7,243 & 23,820 & $\bullet$ \\
P0,6 & 27,090 & 7,867 & 29,635 & $\bullet$ \\
P0,8 & 25,096 & 8,857 & 26,860 & $\bullet$ \\
ES & 25,852 & 5,045 & 27,090 & $\bullet$ \\
EP0,6 & 26,081 & 7,350 & 27,325 & $\bullet$ \\
EP0,8 & 25,153 & 8,721 & 26,680 & $\bullet$ \\
\hline
\end{tabular}

Legenda: Todas as variáveis estão expressas na forma de X(média); $\mathrm{S}($ desvio padrão); \#distribuição assimétrica; • distribuição simétrica; $\alpha=5 \%$.

$\mathrm{CS}=$ grupo controle (inoculado com salina); $\mathrm{P0}, 6=$ grupo peçonha com a dose de $0,6 \mu \mathrm{l} / 100 \mathrm{~g} ; \mathrm{P0}, 8=$ grupo peçonha com a dose de $0,8 \mu \mathrm{l} / 100 \mathrm{~g} ; \mathrm{ES}=$ grupo estresse de 3 horas à $4^{\circ} \mathrm{C}+$ salina; EP0, $6=$ grupo estresse de 3 horas à $4^{\circ} \mathrm{C}+$ peçonha com a dose de $0,6 \mu \mathrm{l} / 100 \mathrm{~g} ; \mathrm{EP} 0,8=$ grupo estresse de 3 horas à $4^{\circ} \mathrm{C}+$ peçonha com a dose de $0,8 \mu \mathrm{l} / 100 \mathrm{~g}$.

CS $\times$ ES

Prova "t" de Student

ou "f"de anova

$\mathrm{P} 0,6 \mathrm{X}$ EP0,6

$\mathrm{t}=3,531 \mathrm{p}=0,0008$

$\mathrm{P} 0,8 \times \mathrm{EP} 0,8$

$\mathrm{t}=0,929, \mathrm{p}=0,503$

$\mathrm{t}=0,052 \mathrm{p}=0,956$

ES $\times$ EP0,6 $\times$ EP0, $8 \mathrm{f}=0,417 \mathrm{p}=0,665$

$\mathrm{PO}, 6 \times \mathrm{P} 0,8 \quad \mathrm{t}=2,003 \mathrm{p}=0,043$

$\mathrm{EP} 0,6 \times \mathrm{EPO}, 8 \quad \mathrm{t}=0,785 \mathrm{p}=0,560$ 
Tabela 5- Distribuição da área das cavidades do coração dos animais, inoculados com peçonha ou salina, com ou sem estresse.

\begin{tabular}{|c|c|c|c|c|}
\hline \multicolumn{5}{|c|}{ ÁREA DAS CAVIDADES $\left(\mathrm{mm}^{2}\right)$} \\
\hline GRUPO & $\mathrm{X}$ & $\mathbf{s}$ & MEDIANA & SIMETRIA \\
\hline CS & 8,397 & 4,732 & 8,310 & \# \\
\hline P0,6 & 8,050 & 4,086 & 7,910 & \# \\
\hline $\mathrm{P} 0,8$ & 8,534 & 4,737 & 8,950 & \# \\
\hline ES & 9,019 & 2,937 & 9,240 & $\bullet$ \\
\hline EP0,6 & 7,064 & 3,763 & 7,215 & \# \\
\hline EPO,8 & 9,153 & 5,144 & 10,145 & \# \\
\hline
\end{tabular}

Legenda: Todas as variáveis estão expressas na forma de X(média); S(desvio padrão); \#distribuição assimétrica; • distribuição simétrica; $\alpha=5 \%$.

$\mathrm{CS}=$ grupo controle (inoculado com salina); $\mathrm{P0}, 6=$ grupo peçonha com a dose de $0,6 \mu \mathrm{l} / 100 \mathrm{~g} ; \mathrm{P} 0,8=$ grupo peçonha com a dose de $0,8 \mu \mathrm{l} / 100 \mathrm{~g} ; \mathrm{ES}=$ grupo estresse de 3 horas à $4^{\circ} \mathrm{C}+$ salina; EP0, $6=$ grupo estresse de 3 horas à $4^{\circ} \mathrm{C}+$ peçonha com a dose de $0,6 \mu \mathrm{l} / 100 \mathrm{~g} ; \mathrm{EP} 0,8=$ grupo estresse de 3 horas à $4^{\circ} \mathrm{C}+$ peçonha com a dose de $0,8 \mu \mathrm{l} / 100 \mathrm{~g}$.

Prova "U" de Mann-Whitney ou

" $\mathrm{H}$ " de Kruskall - Wallis

CS $x$ ES $\quad U=1,867, p=0,171$

$\mathrm{P} 0,6 \times \mathrm{EP} 0,6 \quad \mathrm{U}=2,228, \mathrm{p}=0,135$

$\mathrm{P} 0,8 \times E P 0,8 \quad \mathrm{U}=0,071 \mathrm{p}=0,790$

ES $x$ EP0,6 $\times$ EP0, $8 \mathrm{H}=14,153 \mathrm{p}=0,0008$

$\mathrm{P} 0,6 \times \mathrm{P} 0,8 \quad \mathrm{U}=3,078 \mathrm{p}=0,079$

$\mathrm{EP} 0,6 \times \mathrm{EP} 0,8 \quad \mathrm{U}=9,167 \mathrm{p}=0,002$ 
Tabela 6- Distribuição da áreas de necrose dos animais, inoculados com peçonha ou salina, com ou sem estresse.

\begin{tabular}{|c|c|c|c|c|}
\hline \multicolumn{5}{|c|}{ ÁREA DE NECROSE $\left(\mathrm{mm}^{2}\right)$} \\
\hline GRUPO & $\mathrm{X}$ & $\mathbf{s}$ & MEDIANA & SIMETRIA \\
\hline CS & 0,0 & 0,0 & 0,0 & - \\
\hline P0,6 & 0,006 & 0,048 & 0,0 & \# \\
\hline $\mathrm{P} 0,8$ & 0,056 & 0,339 & 0,0 & \# \\
\hline ES & 0,0 & 0,0 & 0,0 & • \\
\hline EP0,6 & 0,156 & 0,570 & 0,0 & \# \\
\hline $\mathrm{EPO}, 8$ & 0,185 & 0,548 & 0,0 & \# \\
\hline
\end{tabular}

Legenda: Todas as variáveis estão expressas na forma de X(média); S(desvio padrão); \#distribuição assimétrica; • distribuição simétrica; $\alpha=5 \%$.

$\mathrm{CS}=$ grupo controle (inoculado com salina); $\mathrm{P} 0,6=$ grupo peçonha com a dose de $0,6 \mu \mathrm{l} / 100 \mathrm{~g} ; \mathrm{P0}, 8=$ grupo peçonha com a dose de $0,8 \mu \mathrm{l} / 100 \mathrm{~g} ; \mathrm{ES}=$ grupo estresse de 3 horas a $4^{\circ} \mathrm{C}+$ salina; EP0, $6=$ grupo estresse de 3 horas à $4^{\circ} \mathrm{C}+$ peçonha com a dose de $0,6 \mu \mathrm{l} / 100 \mathrm{~g}$; EP0, $8=$ grupo estresse de 3 horas à $4^{\circ} \mathrm{C}+$ peçonha com a dose de $0,8 \mu \mathrm{l} / 100 \mathrm{~g}$.

$\mathrm{P} 0,6 \times \mathrm{EP} 0,6$

$\mathrm{P} 0,8 \times \mathrm{EP} 0,8$

$\mathrm{ES} \times \mathrm{EP} 0,6 \times \mathrm{EP} 0,8$

$\mathrm{P} 0,6 \times \mathrm{P} 0,8$

$\mathrm{EPO}, 6 \times \mathrm{EP} 0,8$
Prova "U" de Mann-Whitney

ou " $H$ " de Kruskall-Wallis

$\mathrm{U}=4,665, \mathrm{p}=0,030$

$\mathrm{U}=7,117, p=0,007$

$\mathrm{H}=15,498 \mathrm{p}=0,0004$

$\mathrm{U}=3,852 \mathrm{p}=0,049$

$\mathrm{U}=2,181 \quad \mathrm{p}=0,139$ 
Tabela 7- Distribuição da relação da área de necrose /área do miocárdio dos animais, inoculados com peçonha ou salina, com ou sem estresse.

\begin{tabular}{llccl}
\hline \multicolumn{4}{c}{ RELAÇÃO $\left(\mathbf{m m}^{2}\right)$} \\
\hline GRUPO & X & s & MEDIANA & SIMETRIA \\
CS & 0,0 & 0,0 & 0,0 & $\bullet$ \\
P0,6 & 0,001 & 0,004 & 0,0 & $\#$ \\
P0,8 & 0,004 & 0,023 & 0,0 & $\#$ \\
ES & 0,0 & 0,0 & 0,0 & $\bullet$ \\
EP0,6 & 0,010 & 0,038 & 0,0 & $\#$ \\
EP0,8 & 0,014 & 0,046 & 0,0 & $\#$ \\
\hline
\end{tabular}

Legenda: Todas as variáveis estão expressas na forma de X(média); S(desvio padrão); \#=distribuição assimétrica; • distribuição simétrica; $\alpha=5 \%$.

$\mathrm{CS}=$ grupo controle (inoculado com salina); $\mathrm{PO}, 6=$ grupo peçonha com a dose de $0,6 \mu \mathrm{l} / 100 \mathrm{~g} ; \mathrm{P} 0,8=$ grupo peçonha com a dose de $0,8 \mu \mathrm{l} / 100 \mathrm{~g} ; \mathrm{ES}=$ grupo estresse de 3 horas à $4^{\circ} \mathrm{C}+$ salina; EP0,6= grupo estresse de 3 horas à $4^{\circ} \mathrm{C}+$ peçonha com a dose de $0,6 \mu \mathrm{l} / 100 \mathrm{~g} ; \mathrm{EP} 0,8=$ grupo estresse de 3 horas à $4^{\circ} \mathrm{C}+$ peçonha com a dose de $0,8 \mu \mathrm{l} / 100 \mathrm{~g}$.

$\mathrm{P} 0,6 \times \mathrm{EP} 0,6$

$\mathrm{P} 0,8 \times \mathrm{EP} 0,8$
Prova " $U$ " de Mann-Whitney

$\mathrm{U}=4,665, \mathrm{p}=0,030$

$\mathrm{U}=7,006 \mathrm{p}=0,0081$ 
Fig. 1- Animais submetidos ao estresse de contenção, durante 3 horas à $4^{\circ} \mathrm{c}$ 


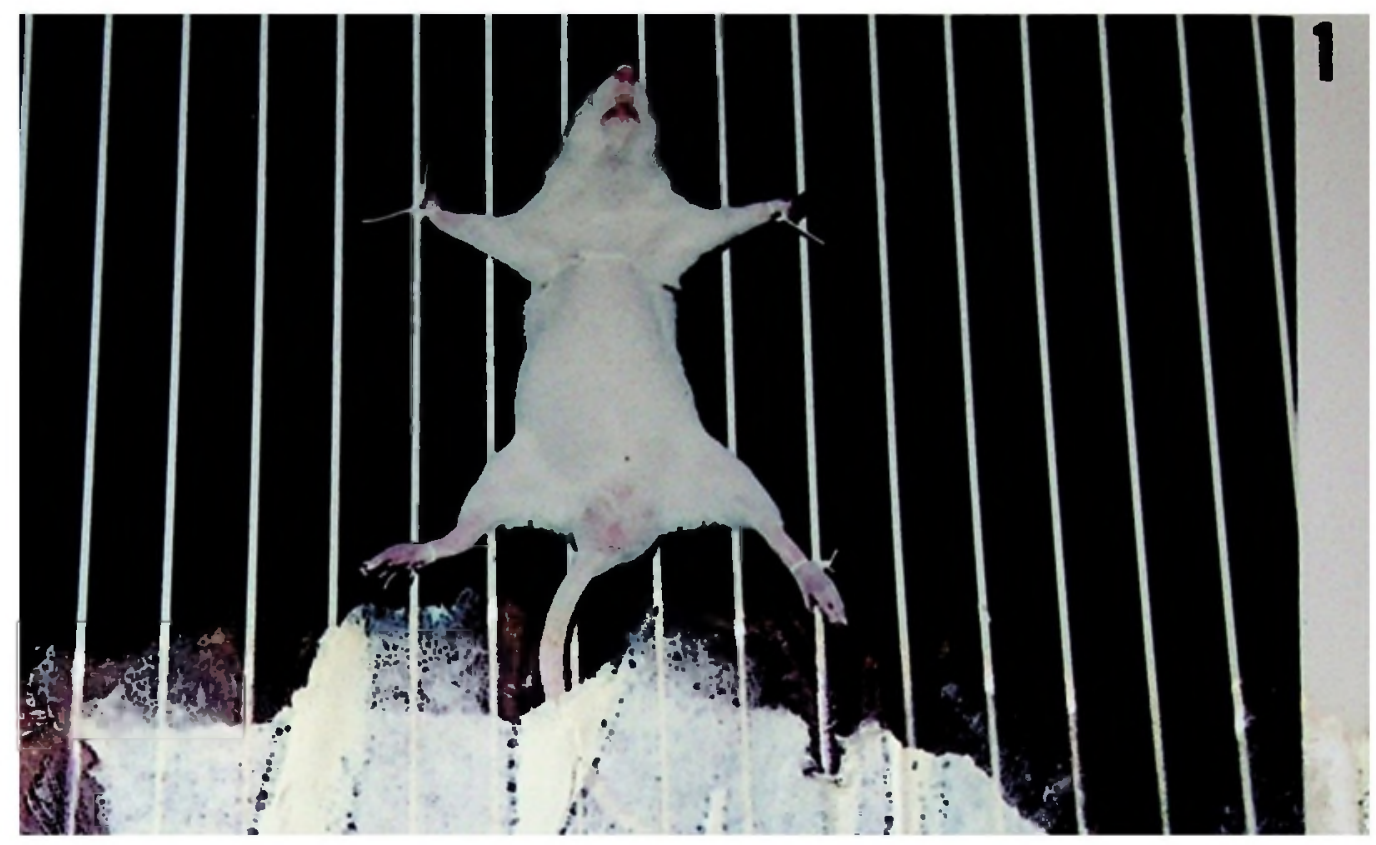

Página com manchas. Não foi possível restaurar o seu conteúdo a partir daqui. 
Fig. 4- Lâmina histológica mostrando os cortes transversais do coração do animal CS-2 do grupo controle.

Fig. 5- Idem fig. 4, animal ECS-2, grupo inoculado com salina $0,6 \mu \mathrm{l} / 100 \mathrm{~g}$ e submetido a estresse durante $3 \mathrm{~h}$ a $4^{\circ} \mathrm{C}$. 


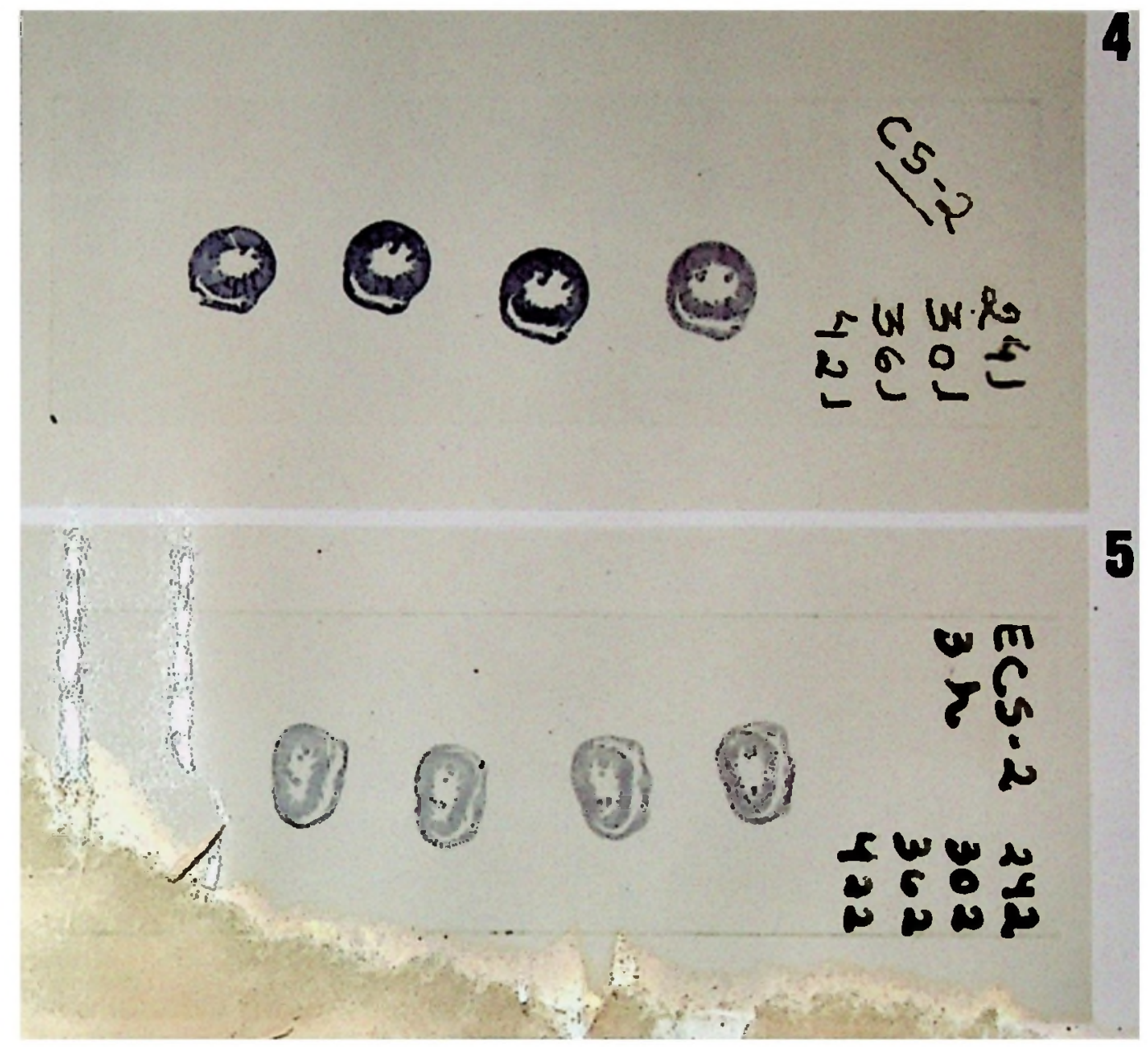

Página com manchas. Não foi possível restaurar o seu conteúdo a partir daqui. 


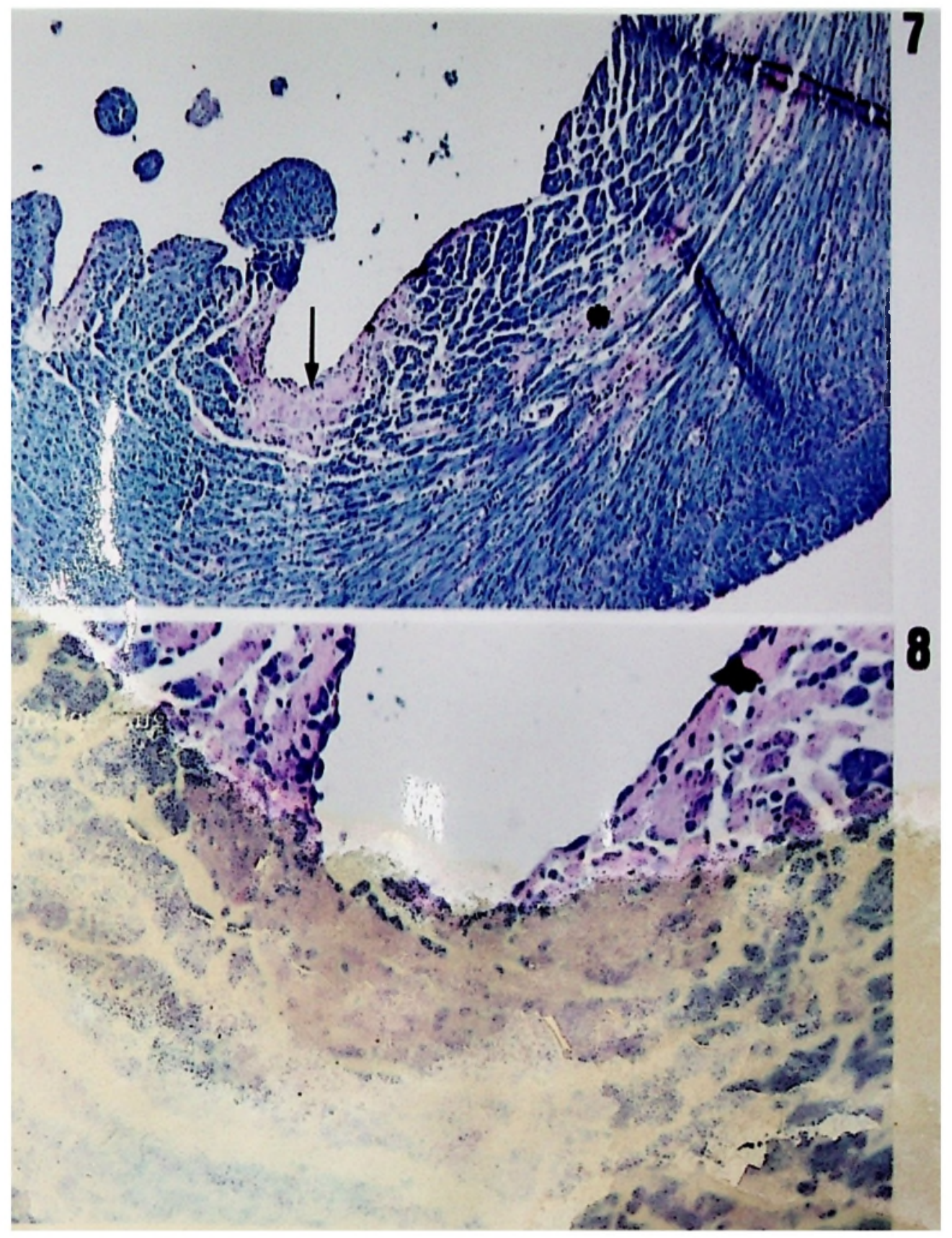


Fig.9- Corte histológico transversal do ápice do coração de animal do grupo $\mathrm{P} 0,8$ mostrando áreas de necrose de fibras cardíacas (asterisco), PTAH, X 430.

Fig.10- Detalhe da figura anterior, mostrando necrose de fibras cardíacas e infiltração inflamatória predominantemente mononuclear, PTAH, X 171? 


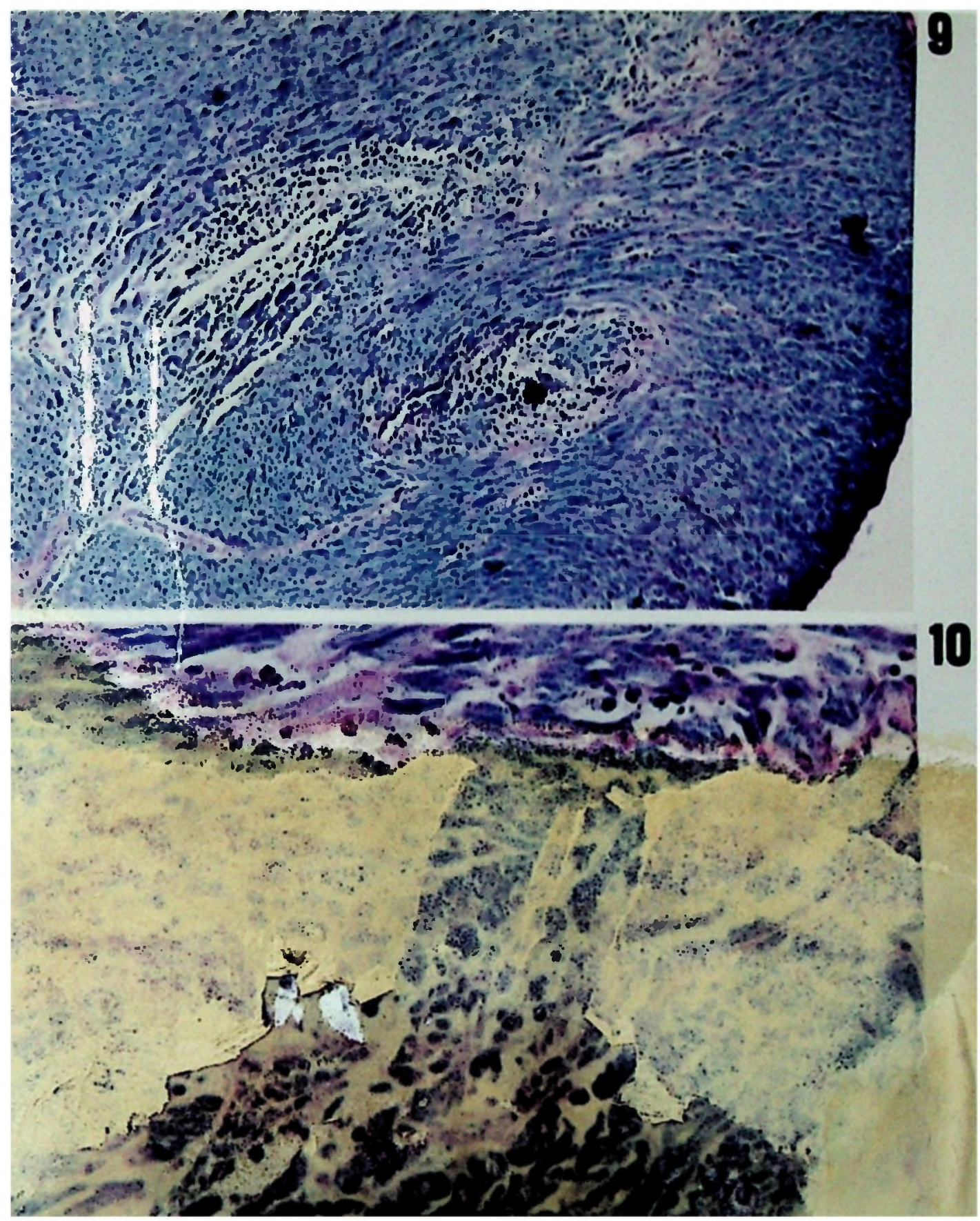


Fig.11- Corte histológico transversal do ápice do coração de animal do grupo EP0,6 mostrando áreas de necrose de fibras cardíacas e infiltração inflamatória (asteriscos), PTAH, X 430.

Fig.12- Detalhe da figura anterior, mostrando áreas de necrose de fibras cardiacas e infiltrado inflamatório predominantemente mononuclear, PTAH, X 17L? 


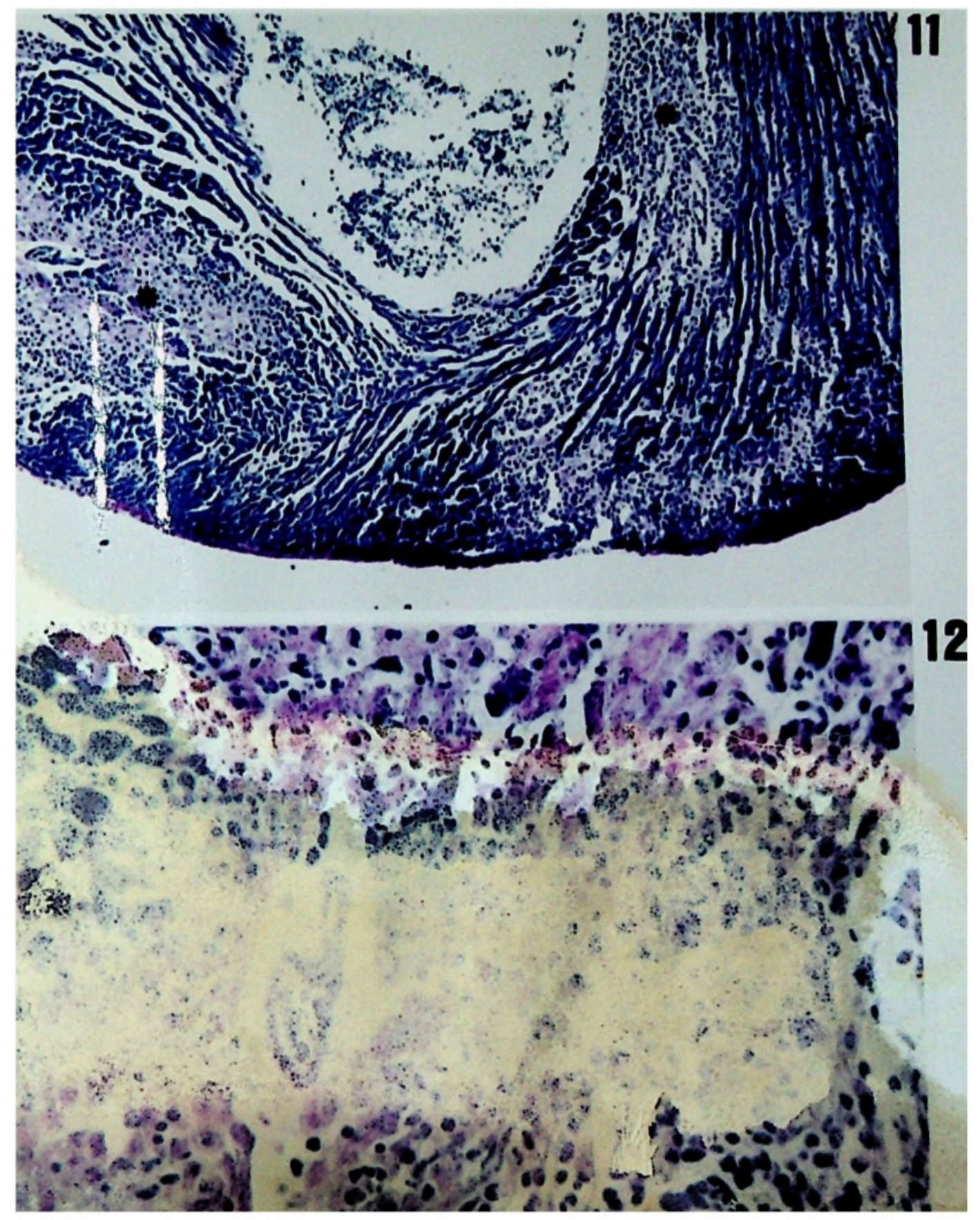




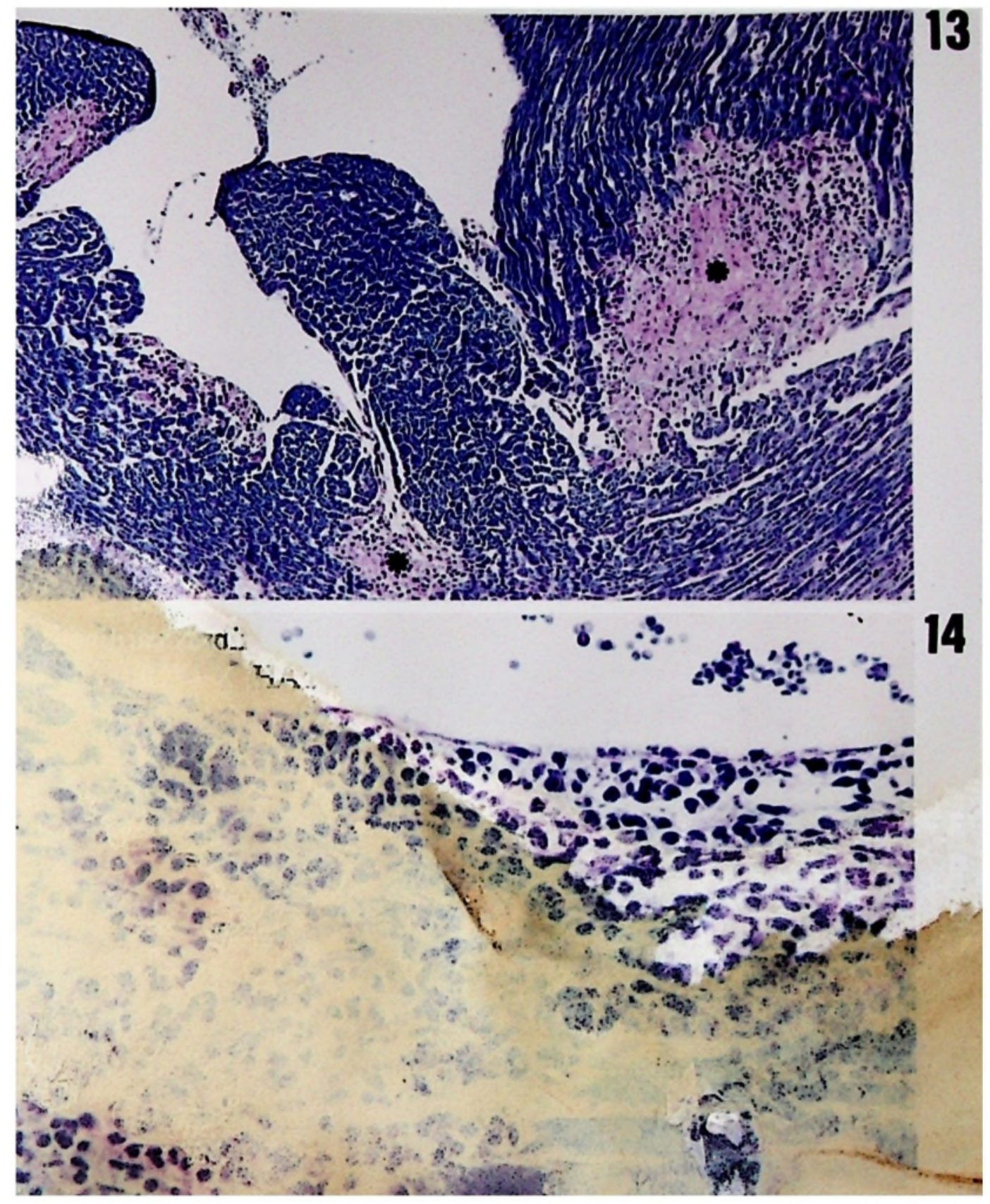


V- DISCUSSÃO 
O presente trabalho foi realizado para avaliar a participação do estresse na patogênese da lesão miocárdica induzida experimentalmente pelo empeçonhamento das abelhas africanizadas. $O$ plano de pesquisa propôs uma avaliação histomorfométrica na qual foram medidas e comparadas as áreas totais, do miocárdio, das cavidades, de necrose e a relação desta com a área de miocárdio intacto dos corações dos grupos controle e dos grupos submetidos ao estresse de contenção a $4^{\circ} \mathrm{C}$.

A cardiotoxicidade no empeçonhamento de himenópteros, dentre os quais a abelha, já foi relatada em vários trabalhos da literatura em pacientes que demonstraram alteraçōes eletrocardiográficas após as picadas.

NAGARATMAN, HUSODO \& JAMES (1988) demonstraram alterações da onda $T$ no eletrocardiograma de um paciente vitima de uma picada de abelha que sobreviveu. FREYE \& ERLICH (1989) relataram 2 casos de pacientes que demonstraram alterações eletrocardiográficas compativeis com infarto agudo do miocárdio após picadas de himenópteros (vespas). Um paciente de 39 anos após ser picado por numerosos "vespões", apresentou dor torácica e no hospital o eletrocardiograma apresentou alterações compativeis com infarto do miocárdio (LEVINE, 1976) AZEVEDO-MARQUES et al (1990) descreveram 4 pacientes com taquicardia, crises de hipotensão e fibrilação ventricular. As autópsias destes pacientes mostraram cardiomegalia, focos de miocitólise e mionecrose miocárdica.

FRANÇA et al (1994) descreveram 5 casos de pacientes vítimas de múltiplas picadas de AA, sendo que 3 pacientes mostraram-se hipertensivos e 1 paciente mostrou 2 áreas de necrose focal subendocárdica encontradas no ventriculo esquerdo no exame histopatológico após a morte.

BARRAVIEIRA et al (1992) avaliaram, do ponto de vista anátomopatológico, uma criança de 11 anos de idade vítima de ataque por enxame de abelhas do gênero Apis. A estimativa do $\mathrm{n}^{\circ}$ de picadas ficou por volta de 800 a 
1000. O doente evoluiu com bradicardia, anisocoria, hemoglobinúria, oligúria, insuficiência renal aguda e choque : A parada cardio-respiratória ocorreu horas após a internação e foi irreversivel. O coração mostrava necrose de fibras subendocárdicas e picnose nuclear.

Com a intenção de investigar a cardiotoxicidade provocada pela PAA, foi desenvolvido um modelo em ratos Wistar (FERREIRA, 1993). Inicialmente foi feita uma avaliação cardíaca, através do eletrocardiograma (ECG) realizado após 5 minutos da inoculação intravenosa de $0,4 \mu \mathrm{l} / 100 \mathrm{~g}$ de PAA. Observaram-se alterações significativas, com aumento da frequeência cardíaca, do comprimento do complexo QRS e da amplitude da onda T (BESTETTI et al, 1991). Foram constatadas também taquicardia sinusal, sem arritmia e elevação do segmento ST (FERREIRA, 1993). A taquicardia sinusal estaria refletindo o estresse dos animais e liberação de catecolaminas. Poderia ser também o reflexo da hipóxia cerebral pela hemólise ou mesmo resposta aos componentes neurotóxicos da PAA, com conseqüente ativação do sistema nervoso simpático (FERREIRA, 1993). A elevação do segmento ST e da onda T retratam sofrimento isquêmico do miocárdio subendocárdico do ventrículo esquerdo (FERREIRA, 1993).

Foi avaliada também no modelo, a noradrenalina tecidual cardíaca, inoculando-se $1,5 \mathrm{ul} / 100 \mathrm{~g}$ de PAA nas diferentes vias. $O$ grupo que apresentou diminuição de noradrenalina, sugerindo liberação desta pelo tecido, foi o inoculado por via intravenosa (FERREIRA et al, 1993/94). A morte rápida dos animaıs pode ser devido a alterações funcionais induzidas por este mediador (FERREIRA et al, 1993/94).

Para avaliação mais detalhada da lesão cardiaca, foi inoculada pela via intravenosa $0,8 \mu \mathrm{l} / 100 \mathrm{~g}$ de PAA, dose equivalente a $\mathrm{DL}_{50}$. Foram examinados animais sacrificados $1 \mathrm{~h}, 4 \mathrm{~h}$ e $24 \mathrm{~h}$ após a inoculação (FERREIRA et al, 1995).

Os animais observados $\mathrm{lh}$ após a inoculação da PAA apresentaram lesão miocárdica do tipo miocitólise coagulativa sem infiltrado inflamatório. Nos 
animais observados $4 \mathrm{~h}$ após a inoculação de PAA, foi observada miocitólise e mionecrose coagulativa associada com infiltrado inflamatório polimorfonuclear na periferia da lesão e nos animais observados 24 h após a inoculação da PAA foi observada a necrose coagulativa de fibras miocárdicas, às vezes envolvendo pequenos focos, outras vezes acometendo extensas áreas similares ao infarto do miocárdio no ápice do ventrículo esquerdo. Um intenso infiltrado inflamatório foi encontrado nessas áreas de lesão, com a predominância de células mononucleares (FERREIRA et al, 1995).

Foram medidos também os níveis de enzimas séricas no soro e foram observados aumentos das enzimas CK, AST, LD e também da $\mathrm{Hb}$. Este aumento de enzimas mostrou-se significante nos 3 grupos observados enquanto o nivel de $\mathrm{Hb}$ mostrou-se elevado nos grupos de $1 \mathrm{~h}$ e $4 \mathrm{~h}$, voltando aos niveis normais após 24h. A análise histoquímica das enzimas mostrou inativação das enzimas SD, CO e MAO no centro das lesões e inativação parcial na periferia (FERREIRA et al, 1995). Estes achados sugerem efeitos sistêmicos da PAA, sendo o coração um dos órgãos alvos.

O mecanismo de lesão cardiaca pode ser devido a vários fatores e de acordo com os resultados obtidos nos trabalhos citados, algumas hipóteses foram levantadas em relação à patogênese da lesão cardiaca.

1) Lesão tóxica direta. Acredita-se que os principais componentes tóxicos da PAA, ou seja, a melitina e a fosfolipase sejam as principais causadoras de danos já que ambas são citolíticas inespecificas e atuam sinergicamente na lise de membranas biológicas (HABERMANN, 1972; OWNBY et al, 1997), além disso, a rabdomiólise, rabdomionecrose e necrose epitelial, assim como a hemólise intravascular maciça e cardiomionecrose foram observadas nestes trabalhos muito precocemente (FERREIRA, 1990; AZEVEDO-MARQUES, FERREIRA \& COSTA, 1992; FERREIRA, 1993). 
2) Lesão hipóxica: Um evento muito importante está envolvido nesta hipótese a hemólise intravascular. Os animais mostraram um alto grau de hemólise, podendo, com isso, causar desequilibrios na homeostasia ácido-básica, metabólica e hemodinâmica, podendo se desenvolver coagulação intravascular disseminada e morte. A hipóxia miocárdica poderia produzir necrose celular, porém sabe-se que as fibras musculares são resistentes à hipóxia apresentando necrose somente várias horas após a inoculação da PAA. Não foi isto o que ocorreu, pois a lesão mostrou-se precoce, apenas lh após a inoculação de PAA (FERREIRA, 1993; FERREIRA et al, 1995).

3) Lesão cardiaca mediada pela histamina: os componentes mastocitolíticos diretos e indiretos da PAA, o peptídeo degranulador de mastócitos (MCDpeptideo), a melitina e a fosfolipase, seriam os responsáveis pela lise dos mastócitos e conseqüente liberação de histamina. Como no empeçonhamento há grande liberação de histamina que se soma à quantidade já existente desta na PAA, ocorreria uma vasodilatação na microcirculação sistêmica com perda do tônus e estagnação periférica do sangue. À nivel coronariano, ocorre vasoconstriç̧ão. Baseado nestes dados, ocorrendo a mastocitólise, o excesso de histamina provocaria efeitos cardiacos, levando à uma hipóxia e necrose de fibras musculares (FERREIRA, 1993)

4)Lesão por inativação enzimática. A histoenzimologia mostrou inativação das enzimas que partıcipam do ciclo de Krebs e da cadeia respiratória: succinato desidrogenase, citocromoxidase e adenosina trifosfatase. A teoria diz que se houver um bloqueio direto das enzimas respiratória, haverá diminuição acentuada e parada de produção e utilização de ATP pelas vias aeróbicas. Por este mecanismo ocorreria morte celular por colapso energético e, já que esse mecanismo é inespecífico, a inativação enzimática explicaria não só a lesão miocárdica como também de outras células, culminando com felência de múltiplos órgãos (FERREIRA, 1993). 
5) Lesão catecolaminogênica: Os animais, devido às circunstâncias, estavam submetidos à situaç̃es de grande estresse, com hiperestimulação do sistema nervoso simpático. Este dado evidencia-se nos animais analisados $\mathrm{lh}$ após a inoculação de PAA, porque mostram lesões sugestivas de catecolaminas segundo BAROLDI (1975). FERREIRA et al (1995) demonstraram diminuição de noradrenalina tecidual cardiaca nos animais inoculados pela via intravenosa o que também é sugestivo de estresse, além do ECG ter detectado uma taquicardia sinusal, que poderia estar refletindo o excesso de catecolaminas circulantes. De qualquer modo, a PAA já possui uma pequena quantidade de catecolaminas, que poderia somar seus efeitos com os autofarmacodinâmicos da PAA.

De acordo com as hipóteses levantadas, chega-se à conclusão de que haveria uma sexta hipótese para a patogênese da lesão cardiaca: a multifatorial.

6) Lesão cardíaca multifatorial: nesta hipótese consideramos a toxidade direta da PAA nas membranas dos miocardiócitos pela melitina e fosfolipase, a hemólise, estagnação periférica do sangue pela ação histamínica e aumento do trabalho das fibras cardiacas por ação das catecolaminas poderiam produzir uma hipóxia miocárdica devido à pouca oferta de oxigênio e aumento relativo do trabalho cardiaco. O excesso de catecolaminas e de histamina circulantes provocaria desequilíbrios na oferta e demanda de oxigênio ao coração. A inativação das enzimas respiratórias provocaria acentuada diminuição da sintese e utilização do ATP. Estes dados, tomados em conjunto, serıam responsáveis pela miocitólise e mionecrose miocárdica (FERREIRA, 1993).

Frente à estas hipóteses, a linha de pesquisa iniciada no começo dos anos 90 continua seu desenvolvimento através de novos experimentos na tentativa de elucidar a questão. No presente trabalho, a ênfase foi dada no papel desempenhado pelo estresse na patogênese da lesão cardíaca provocada pela PAA.

Como disse Selye em 1978 "Pode-se pensar que somente um dano físico ou mental intenso pode causar estresse, porém isto é um pensamento equivocado, 
pois o simples fato de atravessar uma rua movimentada pode ativar a resposta do organismo ao estresse. $O$ estresse é tão necessário quanto nocivo para o individuo, é o tempero da vida, porque qualquer emoção, qualquer atividade causa estresse...O mesmo estresse que torna uma pessoa doente pode ser um estimulo para outra". Estas poucas palavras incluem uma série de importantes declarações como o problema da natureza fisiológica ou não fisiológica do estresse e sua relação complexa com as doenças, pelo fato de que uma variedade enorme de situações, que vão desde um exercício fisico intenso até fortes emoções, podem causar estresse (OTTAVIANI \& FRANCESCHI, 1996).

Inicialmente o que é o estresse? De acordo com Selye em 1978, "o estresse é definido como sendo uma resposta não específica do organismo à qualquer exigência" Esta é uma definição geral, provavelmente muito ampla, já que o problema é provavelmente conhecido desde os fisicos gregos e a medicina Asteca (OTTAVIANI \& FRANCESCHI, 1996).

$O$ estudo do estresse tornou-se um tópico cientifico quando as mudanças encontradas na estrutura e composição quimica do corpo puderam ser estudadas com acurácia. A totalidade dessas mudanças - a síndrome do estresse - é chamada de "síndrome de adaptação geral" e se desenvolve em três estágios: (1) a reação de alarme, (2) o estágio de resistência (3) o estágio de exaustão. Os sistemas nervoso e endócrino (ou hormonal) estão envolvidos particularmente na manutenção da resistência durante o estresse (OTTAVIANI \& FRANCESCHI, 1996).

A ambigüidade fundamental, quando se vai estudar o estresse, é o fato de que o fenômeno descrito tem dois lados inter-relacionados: o estímulo e a resposta. Selye, em 1978, criou um neologismo e introduziu a palavra "estressante" para o agente causador do estresse e "estresse" para a condição resultante. Como já foi dito, uma variedade enorme de estimulos podem induzır o aparecimento da "sindrome do estresse", só que, apesar da existência dessa varıedade de estimulos, 
a resposta que eles provocam foi determinada por características comuns a estes estímulos (OTTAVIANI \& FRANCESCHI, 1996).

Os agentes estressantes têm o cérebro como alvo primário, particularmente o hipotálamo (KORNER, 1979; OTTAVIANI \& FRANCESCHI, 1996). Sinais fundamentais, como o hormônio corticotrópico, são liberados deste órgão.

Em reações de defesa, como a provocada pelo estresse, o hipotálamo é estimulado, desencadeando uma resposta do sistema nervoso simpático com descarga de adrenalina. Essa reação causa um aumento na pressão sangüinea e taquicardia, com conseqüente aumento do débito cardiaco, além de provocar vasoconstricção renal e intestinal. Todos estes eventos promovem intensa liberação de catecolaminas pelo sistema nervoso autônomo do individuo (KORNER, 1979, OTTAVIANI \& FRANCESCHI, 1996). HASHIGUCHI et al (1997) desenvolveram um estudo em ratos submetidos a um tipo de estresse que simulava um terremoto e observaram que a noradrenalina é liberada simultaneamente em regiões extracelulares da porção posterior do hipotálamo e núcleo paraventricular. Essa liberação é acompanhada por um aumento na pressão sangüinea e ritmo cardíaco, assim como os níveis plasmáticos de noradrenalina, adrenalina e corticosterona. Essa liberação simultânea de noradrenalina pelo hipotálamo e núcleo paraventricular sugere que estas regiões estão incluídas numa resposta de defesa central integrada (HASHIGUCHI et al. 1997). Uma maior liberação de noradrenalina provocada pela PAA (FERREIRA et al, 1993) já tinha sido observada. Já admitia-se a hipótese de que uma descarga de catecolaminas cardiacas, provocada pelo estresse, aumentaria a toxicidade de veneno (STAHNKE, 1965).

Os efeitos do estresse de contenção já foram demonstrados em porcos que foram amigdalectomizados (corpo amigdalóide do sistema límbico) comparados a porcos normais, mostrando que naqueles, o nivel de catecolaminas sangǘneas mostraram-se elevados assim como apresentaram taquicardia e até focos de 
necrose (JOHANSSON et al, 1982). Da mesma forma um estímulo elétrico na porção posterior do hipotálamo de ratos induz a ativação do sistema simpático e provoca taquiarritimias ventriculares (CRAMBERS et al, 1996). Experimentos administrando-se catecolaminas, como a adrenalina, e estimulando-se o hipotálamo de macacos mostraram evidências de que a liberação de catecolaminas é capaz de causar lesão de células miocárdicas (COWAN, GIDDENS \& REICHENBACH, 1983). Em humanos, o feocromocitoma está associado com lesão de células miocárdicas, assim como em gatos adrenalectomizados o estimulo hipotalâmico, que resulta numa descarga simpática, também é capaz de lesar células miocárdicas (COWAN, GIDDENS \& REICHENBACH, 1983). O efeito cardiotóxico das catecolaminas é mediado pelo aumento do influxo transmembrana dos ions cálcio, que provoca uma diminuição dos niveis de ATP. O aumento do cálcio intracelular resulta num agrupamento de células miocárdicas e mineralização da mitocôndria. A mineralização da mitocôndria além de indicar aumento de cálcio intracelular, indica lesão celular irreversivel (COWAN, GIDDENS \& REICHENBACH, 1983).

Frente às evidências encontradas na literatura e resultados anteriores que levam à hipótese de uma lesão catecolaminogênica, que poderia estar presente em uma pessoa atacada por um enxame de abelhas, o presente trabalho enfatizou a contribuição do estresse na patogenia da lesão cardiaca induzida experimentalmente pela PAA.

Nas medidas de área total, apenas o grupo controle e o grupo controle com estresse apresentaram uma diferença estatisticamente significante e essa diferença se repete quando compara-se a área de miocárdio. $O$ grupo com a dose de $0,6 \mu \mathrm{l} / 100 \mathrm{~g}$ de peso e o grupo com a dose de $0,8 \mu \mathrm{l} / 100 \mathrm{~g}$ de peso, ambos sem estresse, quando comparados, apresentaram diferença estatisticamente significante em relação à área de miocárdio. A respeito desses dados é necessária uma posterior investigação. 
A área das cavidades não apresentou diferença estatisticamente significante em nenhum grupo. Nas áreas de necrose, como suspeitava-se, tanto o grupo injetado com PAA na dose de $0,6 \mu \mathrm{l} / 100 \mathrm{~g}$ de peso de peçonha e submetidos ao estresse quanto $\circ$ grupo com a dose de $0,8 \mu \mathrm{l} / 100 \mathrm{~g}$ e submetidos ao estresse apresentaram diferença estatisticamente significante quando comparados aos grupos empeçonhados sem estresse, e, conseqüentemente, sua relação com a área do miocárdio intacto também. A suspeita de que o estresse aumenta a toxicidade dos venenos já era discutida por STAHNKE (1965). Também já foi demonstrado que o empeçonhamento por escorpião é caracterizado por uma "overdose" catecolaminogênica, sugerindo uma estimulação adrenérgica por algum componente da peçonha de escorpião que resulta na maioria dos casos em uma insuficiência cardíaca congestiva ou edema pulmonar (GUERON \& YARON, 1970). Já foi demonstrado que a administração de catecolaminas como a adrenalina e também a estimulação do sistema nervoso simpático, com descarga de adrenalina, através da submissão do animal ao estresse de contenção, é capaz de causar lesões em células miocárdicas (JOHANSSON et al, 1982; COWAN, GIDDENS \& REICHENBACH, 1983). FERREIRA et al (1995) demonstraram diminuição de noradrenalina tecidual cardíaca nos animais inoculados pela via intravenosa, o que também é sugestivo de estresse, além do ECG ter detectado uma taquicardia sinusal, que poderia estar refletindo o excesso de catecolaminas circulantes. De qualquer modo, a PAA já possui uma pequena quantidade de catecolaminas, que poderia somar seus efeitos com os autofarmacodinâmicos da PAA. O resultado obtido pode sugerir que a lesão encontrada e potencializada pelo estresse, de acordo com os dados da literatura, seja mais uma das provocadas pelo excesso de catecolaminas (SZAKACS \& MEHLMAN, 1960; OLIVEIRA et al, 1986; GUERON \& YARON, 1970).

Quando comparamos o grupo inoculado com PAA na dose de $0,6 \mu \mathrm{l} / 100 \mathrm{~g}$ de peso de peçonha e o grupo inoculado com PAA na dose de $0,8 \mu \mathrm{l} / 100 \mathrm{~g}$, ambos 
submetidos ao estresse, em relação à área de necrose, não encontramos diferença estatisticamente significante.

O estudo morfológico mostrou que, segundo os critérios de Baroldi (1975), a lesão encontrada foi do tipo necrose de fibras miocárdicas (coagulativa), acometendo ora focos pequenos, ora grandes áreas do miocárdio ventricular esquerdo, apresentando perda da capacidade tintorial do tecido cardiaco, às vezes com homogeneização citoplasmática e desaparecimento nuclear e acompanhado por infiltrado inflamatório constituido de leucócitos, predominantemente mononucleares, e poucos polimorfonucleares, permeando as áreas de lesão. A porção interna do miocárdio necrótico apresenta alongamento com redução do diâmetro das fibras musculares. Seus núcleos desaparecem subseqüentemente, enquanto o aparato miofibrilar ainda mostra-se visível com aparente aumento no comprimento dos sarcômeros. Os focos pequenos de necrose mostraram-se com caracteristicas da miocitólise coagulativa com hipercontração das fibras cardíacas ou segmentos desta, associada com estiramento e quebra das miofibrilas nos outros segmentos da célula ou de células adjacentes. Este padrão está associado com bandas irregulares e transversas, variando em tamanho e largura, que parece ser resultado de uma coagulação de sarcômeros hipercontraidos. Estes achados sugerem o termo "miơcitólise coagulativa" para este padrão de lesão. Infiltrado mononuclear pode estar presente. As lesões encontradas nos grupos experimentais mostraram-se predominantemente no ápice do ventriculo esquerdo, o lado direito do coração foi preservado. A base ventricular esquerda também exibiu lesão, porém com freqüência menor que o ápice, confirmando os resultados de FERREIRA (1993).

Algumas conclusões podem ser obtidas a partir dos resultados encontrados:

A respeito da área do miocárdio, o aumento do grupo estresse salina comparativamente ao grupo controle salina, pode ser devido ao acaso. Todavia, este é um dado que necessita posterior investigação. 
Ratos Wistar inoculados pela via intravenosa, em dose subletal, por PAA em ambas as doses de $0,6 \mu \mathrm{l} / 100 \mathrm{~g}$ de peso e $0,8 \mu \mathrm{l} / 100 \mathrm{~g}$ de peso, e submetidos ao estresse de contenção de $3 \mathrm{~h}$ a $4^{\circ} \mathrm{C}$ apresentaram áreas de necrose do miocárdio significativamente maiores que os ratos Wistar inoculados com PAA, em ambas as doses, não submetidos ao estresse de contenção de $3 \mathrm{~h}$. Associado a este achado temos o resultado do estudo morfológico que mostra extensas áreas de necrose de coagulação que é considerada uma lesão semelhante ao infarto do miocárdio associada com pequenas áreas de miocitólise coagulativa que é considerada característica de lesão provocada pela liberação de catecolaminas, sugerindo que estas têm um papel primário na patogênese da miocitólise coagulativa (BAROLDI, 1975). Além disso, já foi constatada a liberação de noradrenalina tecidual cardíaca induzida pela PAA (FERREIRA et al, 1993), além de haver uma pequena quantidade de adrenalina na PAA (HABERMANN, 1972), que somaria seus efeitos.

Diante de todas as evidências encontradas, é possivel que a lesão cardiaca provocada pela PAA, seja mais uma daquelas provocadas pelas catecolaminas (SZAKACS \& MEHLMAN, 1960, OLIVEIRA et al, 1986; GUERON \& YARON, 1970).

Não se pode, neste ponto, afirmar que a lesão encontrada seja apenas catecolaminogênica, mas, sim, considerar a hipótese multifatorial, na qual o papel do estresse, de acordo com nossos resultados, é crucial na colaboração da patogênese da lesão cardíaca encontrada. Em resumo, haveria toxicidade direta às membranas dos miocárdiócitos pela melitina e fosfolipase, pela hemólise e estagnação periférica do sangue, por ação da histamina, aumento do trabalho das fibras cardíacas e aumento do cálcio intracelular e, conseqüentemente, mineralização da mitocôndria, por ação das catecolaminas, resultando em hipóxia miocárdica. 
Finalizando, os achados deste trabalho podem ser paralelos com os encontrados em vítimas humanas, indicando que as vítimas de múltiplas picadas de abelhas devem ser cuidadosamente monitoradas, dando mais importância ao coração, e principalmente não se administrando adrenalina como é a conduta de praxe tomada nos casos de anafilaxia causado por uma ou algumas picadas. 


\section{VI- RESUMO}

O presente trabalho estuda o papel patogenético do estresse potencializando a lesão cardiaca induzida pelo empeçonhamento experimental por abelhas africanizadas em ratos Wistar, através da histomorfometria da lesão.

A análise histológica dos grupos empeçonhados com e sem estresse demonstrou uma lesão semelhante ao infarto do miocárdio acometendo ora focos pequenos, ora grandes áreas do miocárdio ventricular esquerdo, apresentando perda da capacidade tintorial do tecido cardíaco, às vezes com homogeneização do citoplasma e da fibra muscular, desaparecimento nuclear, acompanhado por infiltrado inflamatório constituído predominantemente por leucócitos mononucleares e poucos leucócitos polimorfonucleares, permeando as áreas de lesão. Os focos de necrose mostraram-se com características da miocitólise coagulativa.

A análise morfométrica mostrou que os grupos empeçonhados com estresse, apresentaram uma área de necrose significativamente maior que àquela dos grupos empeçonhados sem estresse.

Este trabalho mostra que o estresse potencializa a lesão cardiaca induzida pelo empeçonhamento experimental por abelhas africanizadas em ratos Wistar. Discute-se o mecanismo que levou à esta potencialização. 


\section{VII- SUMMARY}

The present study investigates the pathogenetic role of stress as a potentiating factor in the heart damage induced by experimental envenomation of Wistar rats with Africanized bee venom, as determined by histomorphometry of the lesions.

Histological analysis of the envenomed groups submitted or not to stress demonstrated a lesion similar to myocardial infarction involving small focal areas or large areas of the left ventricular myocardium. Loss of staining capacity of cardiac tissue was observed, at times with homogenization of the cytoplasm and of muscle fibers, and disappearance of the nucleus accompained by an inflammatory infiltrate predominantly consisting of mononuclear leucocytes and few polymorphonuclear leucocytes permeating the damaged area. The focal points of necrosis showed characteristics of coagulative myocytolisys.

Morphometric analysis showed that the envenomed groups submitted to stress presented a necrotic area significantly larger than those observed in the envenomed groups not submitted to stress.

The present study shows that stress potentiates the cardiac damage induced by experimental envenomation of Wistar rats with Africanized bee venom. The mechanism leading to this potentiation is discussed. 
VIII - REFERÊNCIAS BIBLIOGRÁFICAS 


\section{REFERÊNCIAS BIBLIOGRÁFICAS}

1. Abuelo, J.G. Renal failure caused by chemicals, foods, plants, animal venoms and misuse of drugs. Arch Intern Med 150:505-510;1990.

2. Azevedo-Marques, M.M.; Ferreira D.B.; Costa, R.S.; Cupo, P.; Hering, S.E. Achados clinicos e laboratoriais de 4 acidentes fatais por múltiplas picadas de abelhas africanizadas. Rev Soc Bras Med Trop 23:105106;1990. Supplement.

3. Azevedo-Marques, M.M.; Ferreira, D.B.; Costa, R.S. Rhabdomionecrosis experimentally induced in Wistar rats by Africanized bee venom. Toxicon 30(3):344-348;1992.

4. Barravieira, B.; Goldberg, T.B.L.; Simões, A.B.; Richetti, S.M.Q.; Coelho, K.I.R. Acidente por múltiplas picadas de abelhas. Resultados anatomopatológicos. In: Cong da Soc Bras Med Trop 28, Belém, 1992. Anais. Soc Bras Med Trop, Belém, p.113.

5. Barnard, J.H. Studies of 400 Hymenoptera sting deaths in the United States. J Allergy Clin Immunol 52(5):259-264;1973.

6. Baroldi, G. Different types of myocardial necrosis in coronary heart disease: a pathophysiologic review of their functional significance. Am Heart J 89(6):742-752;1975. 
7. Barss, P. Renal failure and death after multiple stings in Papua New Guinea. Med J Aust 151(11/12):659-663;1989.

8. Beccari, M.; Castiglione, A.; Cavaliere, G.; D’Aloya, G.; Fabbri, C.; Losi, B.; Ranzini, C.; Romagnoni, Sorgato G. Direct tubular toxicity of hymenoptera venom. Nephron 65:159;1993.

9. Berquó, E.S.; Souza, J.M.P.; Gotlieb S.L.D. Bioestatística. $1^{\text {a }}$ ed. Rev. São Paulo, Editora Pedagógica e Universitária Ltda. 1981.

10. Bestetti, R.; Ferreira, D.B.; Costa, R.S.; Azevedo-Marques, M.M.; Pinto, L.Z.; Oliveira, J.S.M. Eletrocardiographic changes evoked by injection of Africanized bee venom in Wistar rats. $\mathbf{J}$ Mol Cell Cardiol 23:S81;1991. (Suppl V).

11. Bousquet, J.; Huchard, G.; Michel F.B. Toxic reactions induced by hymenoptera venom. Ann Allergy 52:371-374;1984.

12. Brandeburgo, M.A.M. Agressive behavior of bees. Ciência e Cultura 42(12) $1025-1034 ; 1990$.

13. Camazine S.; Morse R.A. The Africanized honeybee. Am Scient 76:465-471, 1988.

14. Cochran T.A.; Stenfanka J.; Moore C.; Saik R.P. Citotoxic-free radicals in stress ulceration. S Forum 33:159-161;1982. 
15. Cohen, S.G. The Pharaoh and the wasp. Allergy Proc 10(2):149$151 ; 1989$.

16. Collins, A.M.; Rinderer, T.E.; Harbo, J.R.; Bolten, A.B. Colony defense by Africanized and European honeybees. Science 218:72-74;1982.

17. Cowan, J.; Giddens, E.W.; Reichenbach D.D. Selective myocardial cell necrosis in nonhuman primates. Arch Pathol Lab Med 107:34-39;1983.

18. Crambers, A.; Monassier, L.; Chapleau, D.; Roegel, J-C.; Feldman, J.; Bousquet, P. GABAergic and Glutaminergic modulation of centrally evoked arrhythmias in rats. Hypertension 27(1)148-154;1996.

19. Diniz Filho, J.A.F.; Malaspina, O. Abelhas Africanizadas nos anos 90. A história mostra que a população aprendeu a conviver com essas abelhas. Ciência Hoje 18(106):73-76;1995.

20. Ebashi, S.; Toyokura, Y.; Momoi, H.; Sugita, H. High creatine phosphokinase activity of sera of progressive muscular dystrophy patients. J Biochemistry $46: 103 ; 1959$.

21. Elgart, G.W. Ant, bee and wasp stings. Dermatol Clin 8(2):229236,1990 .

22. Feinfeld, D.A., Cheng, J.T., Beysolow, T., Briscoe, A.M. A prospective study of urine and serum myoglobin levels in patients with acute rhabdomyolisis. Clin Nefrol 38(4):193-195;1992. 
23. Ferreira, D.B. Envenenamento experimental em ratos com peçonha de abelhas africanizadas: anatomia patológica, enzimas séricas e catecolaminas cardíacas. Dissertação de Mestrado, Departamento de Patologia, Faculdade de Medicina de Ribeirão Preto da Universidade de São Paulo, 1990.

24. Ferreira, D.B. Cardiotoxicidade experimentalmente induzida em ratos wistar por peçonha de abelhas africanizadas. Tese de Doutorado, Departamento de Patologia, Faculdade de Medicina de Ribeirão Preto da Universidade de São Paulo, 1993.

25. Ferreira, D.B.; Costa, R.S.; Oliveira, J.S.M.; Mucillo, G. Cardiac noradrenaline in experimental rat envenomation with Africanized bee venom. Exp Toxic Pathol 45:507-51 1;1993/94.

26. Ferreira, D.B.; Costa, R.S.; Mello de Oliveira, J.A.; Mucillo, G. An infart-like myocardial lesion experimentally induced in Wistar rats with Africanized bee venom. J Pathol 177:95-102;1995.

27. Fletcher, J.E., Jiang, M.S. Possible mechanisms of action of cobra snake venom cardiotoxins and bee venom melittin. Toxicon 31(6):669-695; 1993.

28. França, F.O.S.; Benvenuti, L.A.; Fan, H.W.; Dos Santos, D.O.S.; Hain, S.H., Picchi-Martins, F.R.; Cardoso, J.L.C.; Kamiguti, A.S.: Theakston, R.D.G., Warrell, D.A. Severe and fatal mass attacks by 'Killer' bees (Africanized honey bees - Apis mellifera scutellata) in Brazil: clinicopathological studies with measurement of serum venom concentrations. Quat J Med 87:269-282;1994. 
29. Freye HB, Erlich B. Acute miocardial infarction following hymenoptera envenomation. Allergy Proc 10(2):1 19-126;1989.

30. Gabow, P.A.; Kaehny, W.D.; Kelleher, P.S. The spectrum of rhabdomyolisis. Medicine 61(3):141-152;1982.

31. Gandolfo G., Lambeau G., Lazdunski M., Gottesmann C. Effects on behaviour and EEG of single chain phospholipases $A_{2}$ from snake and bee venoms injected into rat brain: search for a functional antagonism. Pharm \& Toxicol 78:341-347;1996.

32. Gauldie J., Hanson J.M., Rumjanek F.D., Shipolini RA, Vernon CA. The peptide components of bee venom. Eur J Biochem 61:369-376;1976.

33. Gonçalves L.S. The introduction of African Bees (Apis Mellifera adansoni) into Brazil and some comments on their spread in South America. Am Bee J 114(11):414-415; 1974.

34. Gonçalves L.S. Do the Africanized bees of Brazil only stings? Am Bee J 115(1);8-10;1975.

35. Gueron, M., Yaron R. Cardiovascular Manifestations of Severe Scorpion Sting. Chest 57(2):156-162;1970.

36. Habermann, E. Bee and wasp venoms. The biochemistry and pharmacology of their peptides and enzimes are reviewed. Science 177:314-322; 1972. 
37. Hashiguchi, H.; Ye, S.H.; Ross-Cisneros, F.; Alexander, N. Central nitric oxide donors attenuate cardiovascular and central norepinephrine responses to stress. Am J Physiol 41:1447-1453;1997.

38. Johansson, G.; Olsson, K.; Haggendal, J.; Jonsson, L.; Thoren-Tolling, $K$. Effect of stress on miocardial cells and blood levels of catecolamines in normal and amygdalectomized pigs. Can J Comp Med 46(2):176$182 ; 1982$.

39. Kerr, W.E. The History of the Introduction of African Bees in Brazil. S Afr Bee J 39:3-5;1967.

40. Kerr, W.E.; Del Rio, S.L.; Barrionuevo, M.D. Distribuição da abelha africanizada em seus limites ao sul. Ciência e Cultura 34(11):14391442;1982.

41. King, T.P, Sobotka, A.K.; Kochoumian, L.; Lichtenstein, L.M. Allergens of Honey bee venom. Arc Biochem Biophysics 172:661671,1976 .

42. Korner, P.I. Central nervous control of autonomic cardiovascular function in:Berne, M.R., Sperelakis, N., Geiger, R.S. Handbook of Phisiology, section 2, The cardiovascular system:The heart. Maryland, 1979. 
43. Labbé-Jullié, C.; Granier, C.; Alberico, F.; Defendini, M-L.; Ceard, B.; Rochat, H.; Van Rietschoten, J. Binding and toxicity of apamin. Eur $\mathbf{J}$ Biochem 196:639-645;1991.

44. Lello, E. Bee venom: glands intoxication, acidents. Mem Inst Butantan 33(3):821-828;1966.

45. Levine, H.D. Acute myocardial infarction following wasp sting. Am Heart J 91:365-374;1976.

46. Lichtenstein, L.M.; Golden, D.B.K. Postscript to bee stings: delayed “serum sickness". Hosp Pract 18(12):36-46;1983.

47. Mantor, C.P.; Tuggle, W.D.; Perkins, A.T.; Shock, C.K.; Askew A.A.; Tunell, W.P. Stress induced gastric ulcers. C Surgery 46(5):388-389; 1989.

48. Marshall, T.K. Wasp and bee stings. Practitioner 178:712-722;1957.

49. McKenna, W.R. The africanized honey bee. Allergy Proc 1(1):7$10 ; 1992$.

50. Mello, M.L.S. A qualitative analysis of the protein in venoms from Apis mellifera (including A. m. adansoni) and Bombus atratus. J Apic Res $9(3): 113-120 ; 1970$.

51. Mello, M.L.S. O veneno das abelhas. In: Camargo, JMF - Manual de Apicultura. São Paulo: Ed Agronômica Ceres. pp - 143-145,1972. 
52. Mendes, R.P.; Meira, D.A.; Molinari, H.; Rodrigues, P.S.; Coelho, K.Y.R. Acidentes por múltiplas picadas de abelhas. Arq Bras Medicina 64(2):81-88;1990.

53. Michener, C.D. The brazilian bee problem. Annu Rev Entomol 20:399-416;1975.

54. Muñoz-Arizpe, R.; Valencia-Espinoza, L.; Velasquez-Jones, L.; AbarcaFranco, C.; Gamboa-Marrufo, J.; Valencia-Mayoral, P. Africanized bee stings and pathogenesis of acute renal failure. Nephron 61:478;1992.

55. Murray, J.A. A case of multiple bee stings. Cent Afr J Med 10(7):249$251 ; 1964$.

56. Nace, L.; Bauer, P.; Lelarge, P., Bollaert, P.E.; Larcan, A.; Lambert, H. Multiple european wasp sting and acute renal failure. Nephron 61:477;1992.

57. Nagaratnam N.; Husodo, H.; James, W.E. Eletrocardiographic changes following bee-sting anaphilaxis. J R Soc Med 81:420-421;1988.

58. Nelson, D.R.; Collins, A.M.; Hellmich, R.L.; Jones, R.T.; Helm, R.M.; Squillace, D.L.; Yunginger, J.W. Biochemical and immunochemical comparison of africanized and european honeybee venoms. J Allergy Clin Immunol 85:80-85; 1990 . 
59. O'Connor, R.; Stier, R.A.; Rosenbrook, J.R.W.; Erickson, R.W. Death from "wasp" sting. Ann Allergy 22(7):385-393;1964.

60. Okamoto, T.; Isoda, H.; Kubota, K.; Takahata, T.; Kishi, T.; Nakamura, T.Y.; Muromachi, Y.; Matsui, Y., Goshima, K. Melittin cardiotoxicity in culture mouse cardiac myocytes and its correlation with calcium overload. Toxicol Appl Pharmacol 133:150-163;1995.

61. Oliveira, J.S.M.; Mucillo, G.; Scozzafave-Neto, F.; Maffia, L.G. Changes in myocardial norepinephrine levels in response to stress, exercise and aging in control and T. cruzzi-infected rats. Braz J Med Res 19:367$374 ; 1986$.

62. Ordman, D. Bee stings in South Africa. S Afr Bee J 42(2):9-15; 1969.

63. Ottaviani, E; Franceschi, C. The neuroimmunology of stress from invertebrates to man. Prog in Neurobiol 48:421-440;1996.

64. Ownby, C.L.; Powell, J.R.; Jiang, M-S.; Fletcher, J.E. Melittin and phospholipase A2 from bee (Apis mellifera) venom cause necrosis of murine skeletal muscle in vivo. Toxicon 35(1):67-80;1997.

65. Parrish, H.M. Analysis of 400 fatalities from venomous animals in the United States. Am J Med Sci 245:129-141;1963.

66. Perlman, E. Near fatal allergic reactions to bee and wasp stings: a review and report of seven cases. Mt Sinai J Med (NY) 22:336-348; 1955. 
67. Raper, R.F.; Fisher, M. McD. Profound reversible myocardial depression after anaphylaxis. Lancet 1:386-388;1988.

68. Reis, M.A. Alterações funcionais e morfológicas na necrose tubular aguda induzida experimentalmente por peçonha de Abelhas Africanizadas em ratas Wistar. Tese de Doutorado, Departamento de Patologia, Faculdade de Medicina de Ribeirão Preto da Universidade de São Paulo, 1995.

69. Reisman, R.E. Insect stings. N Engl J Med 331(8):523-527; 1994.

70. Reisman, R.E.; Livingston, A. Late-onset allergic reactions, including serum sickness, after insect sting. J Allergy Clin Immunol 84(3):331$337 ; 1989$.

71. Renaud, S. Improved restraint-technique for producing stress and cardiac necrosis in rats. J appl Physiol 14:868-869;1959.

72. Rothschild, A.M. Mechanism of histamine release by animals venoms. Mem Inst Butantan 33(2):467-476;1966.

73. Rubenstein, H.S. Bee sting diseases: Who is at risk? What is the treatment? Lancet 1:486-489;1982.

74. Sakhuja, V.; Bhalla A.; Pereira, B.J.G.; Kapoor, M.M.; Bhusnurmath, S.R.; Chugh, K.S. Acute renal failure following multiple homet stings. Nephron 49:319-321;1988. 
75. Schenken, J.R.; Tamisiea, J.; Winter, F.D. Hypersensitivity to bee sting. Report of fatal case and review of literature. Am J Clin Pathol 23:1216$1221 ; 1953$.

76. Schimidt, J.O. Toxinology of venoms from the honeybee genus Apis. Toxicon 33(7):917-927;1995.

77. Schumacher, M.J.; Egen, N.B. Significance of Africanized bees for public health - A Review. Arch Intern Med 155:2038-2043;1995.

78. Schumacher, M.J.; Schmidt, J.O.; Egen, N.B.; Lowry, J.E. Quality, analysis and lethality of European and Africanized honeybee venoms. Am J Trop Med Hyg 43(1):79-86;1990.

7.9. Sert, M.; Tetiker, T.; Paydas, S. Rhabdomyolisis and acute renal failure due to honeybee stings as na uncommon cause. Nephron 65:647;1993.

80. Stahnke, H.L. Stress and toxicity of venoms. Science 150:1456$1457 ; 1965$.

81. Szakacs, J.E.; Mehlman, B. Pathologic changes induced by Lnorepinephrine: quantitative aspects. Am J Cardiol 5:619-627;1960.

82. Taylor Junior, O.R. The past and possible future spread of Africanized honeybees in the Americas. Bee World 58:19-30;1977. 
83. Taylor Junior, O.R. Health problem associated with African bees Ann Intern Med 104:267-268; 1986.

84. Venters, H.D.; Vernier, R.L.; Worthen, H.G.; Good, R.A. Bee sting nephrosis: a syudy of the immunopathologic mechanisms. Am J Dis Child 102:688-689;1961.

85. Vernon, L.P.; Bell, J.D. Membrane structure, toxins and phospholipase $A_{2}$ activity. Pharmac Ther 54(3):269-295;1992.

86. Williams, M.A. Quantitative methods in biology. In: Practical methods in electron microscopy. Editted by Glauber, A.M. Elsevier North-Holland Biomedical Press. Amsterdam, The Nederlands, 1977.

87. Winston, L. The biology and management of Africanized honey bees. Annu Rev Entomol 37:173-193;1992. 
IX - APÊNDICE 


\section{APÊNDICE}

\section{ANÁLISE MORFOMÉTRICA}

Todos os animais tanto dos grupos controle quanto de estresse foram submetidos à análise morfométrica. Os resultados dessa análise estão expressos nas tabelas abaixo, sendo que:

$\mathrm{No}=$ número de cortes

ÁREAF $=$ Área total do corte.

ÁREA = Área do miocárdio.

ÁREA INT = Área das cavidades.

OBS: No grupo $\mathrm{P0}, 8$ alguns animais receberam a mesma numeração, sendo distingüidos pelas respectivas letras $A, B, C$, etc.

\section{GRUPO CONTROLE ( SALINA)}

\begin{tabular}{|c|c|c|c|}
\hline \multicolumn{4}{|c|}{ RATO 1} \\
\hline No & AREAF/mm^ 2 & AREA $/ \mathrm{mm}^{\wedge} 2$ & AREAINT/mm^2 \\
\hline 1 & 38.20 & 31.45 & 6.76 \\
\hline 2 & 43.26 & 35.64 & 7.63 \\
\hline 3 & 42.09 & 34.98 & 7.11 \\
\hline 4 & 41.98 & 34.42 & 7.55 \\
\hline 5 & 40.37 & 33.92 & 6.45 \\
\hline 6 & 37.70 & 32.40 & 5.30 \\
\hline 7 & 36.51 & 31.47 & 5.05 \\
\hline 8 & 34.43 & 29.97 & 4.46 \\
\hline 9 & 31.16 & 27.29 & 3.88 \\
\hline 10 & 28.55 & 24.66 & 3.89 \\
\hline 11 & 29.11 & 25.24 & 3.87 \\
\hline 12 & 26.70 & 22.83 & 3.87 \\
\hline 13 & 24.90 & 20.87 & 4.03 \\
\hline 14 & 22.26 & 20.18 & 2.08 \\
\hline 15 & 15.29 & 11.65 & 3.64 \\
\hline 16 & 11.10 & 9.82 & 1.28 \\
\hline \multicolumn{4}{|c|}{ RATO 2} \\
\hline No & AREAF $/ \mathrm{mm}^{\wedge} \mathbf{2}$ & AREA $/ \mathrm{mm}^{\wedge} \mathbf{2}$ & AREAINT/mm^2 \\
\hline 1 & 37.65 & 27.17 & 10.48 \\
\hline 2 & 39.74 & 29.61 & 10.13 \\
\hline 3 & 42.00 & 31.88 & 10.12 \\
\hline 4 & 41.19 & 31.05 & 10.14 \\
\hline 5 & 38.16 & 29.85 & 8.31 \\
\hline 6 & 37.37 & 29.70 & 7.67 \\
\hline 7 & 33.71 & 26.49 & 7.22 \\
\hline
\end{tabular}




\begin{tabular}{l|lll}
\hline 8 & 30.50 & 23.44 & 7.06 \\
\hline 9 & 30.00 & 23.56 & 6.44 \\
\hline 10 & 24.33 & 20.04 & 4.29 \\
\hline 11 & 23.18 & 18.14 & 5.04 \\
\hline 12 & 19.30 & 15.02 & 4.28 \\
\hline 13 & 13.69 & 12.02 & 1.67 \\
\hline 14 & 8.15 & 7.44 & 0.71 \\
\hline
\end{tabular}

RATO 3

\begin{tabular}{|c|c|c|c|}
\hline No & AREAF $/ \mathrm{mm}^{\wedge} \mathbf{2}$ & AREA/mm^2 & AREAINT/mm^2 \\
\hline 1 & 42.16 & 27.90 & 14.27 \\
\hline 2 & 46.11 & 31.20 & 14.91 \\
\hline 3 & 47.50 & 29.99 & 17.51 \\
\hline 4 & 48.17 & 32.09 & 16.08 \\
\hline 5 & 48.93 & 31.03 & 17.90 \\
\hline 6 & 48.05 & 30.19 & 17.87 \\
\hline 7 & 47.50 & 28.09 & 19.40 \\
\hline 8 & 42.52 & 27.51 & 15.01 \\
\hline 9 & 39.72 & 24.57 & 15.15 \\
\hline 10 & 38.10 & 23.31 & 14.79 \\
\hline 11 & 33.25 & 22.48 & 10.76 \\
\hline 12 & 28.28 & 18.90 & 9.38 \\
\hline 13. & 23.80 & 17.13 & 6.67 \\
\hline 14 & 18.09 & 14.31 & 3.79 \\
\hline 15 & 10.93 & 10.08 & 0.85 \\
\hline \multicolumn{4}{|c|}{ RATO 4} \\
\hline No & AREAF $/ \mathrm{mm}^{\wedge}{ }^{\wedge} 2$ & AREA/mm^2 & AREAINT/mm^2 \\
\hline 1 & 35.24 & 23.54 & 11.70 \\
\hline 2 & 43.05 & 28.28 & 14.77 \\
\hline 3 & 45.08 & 29.75 & 15.33 \\
\hline 4 & 45.70 & 30.55 & 15.15 \\
\hline 5 & 43.85 & 28.93 & 14.92 \\
\hline 6 & 41.86 & 28.17 & 13.69 \\
\hline 7 & 38.81 & 24.78 & 14.03 \\
\hline 8 & 35.02 & 24.26 & 10.76 \\
\hline 9 & 34.33 & 23.28 & 11.04 \\
\hline 10 & 31.62 & 22.44 & 9.18 \\
\hline 11 & 27.82 & 19.64 & 8.18 \\
\hline 12 & 21.77 & $17: 43$ & 4.34 \\
\hline 13 & 17.39 & 13.08 & 4.31 \\
\hline 14 & 13.18 & 11.94 & 1.24 \\
\hline
\end{tabular}




\begin{tabular}{|c|c|c|c|}
\hline \multicolumn{4}{|c|}{ RATO 5 } \\
\hline No & AREAF $/ \mathrm{mm}^{\wedge}{ }^{\wedge} 2$ & AREA $/ \mathrm{mm}^{\wedge} 2$ & AREAINT/mm $/ m^{\wedge} 2$ \\
\hline 1 & 30.61 & 22.29 & 8.32 \\
\hline 2 & 39.76 & 30.80 & 8.97 \\
\hline 3 & 42.28 & 30.41 & 11.86 \\
\hline 4 & 39.39 & 30.85 & 8.55 \\
\hline 5 & 34.55 & 26.51 & 8.04 \\
\hline 6 & 35.68 & 26.29 & 9.39 \\
\hline 7 & 33.27 & 26.01 & 7.26 \\
\hline 8 & 24.35 & 19.50 & 4.85 \\
\hline 9 & 25.29 & 19.97 & 5.32 \\
\hline 10 & 21.34 & 17.62 & 3.72 \\
\hline 11 & 17.99 & 15.56 & 2.43 \\
\hline 12 & 16.02 & 14.65 & 1.37 \\
\hline 13 & 9.82 & 9.27 & 0.55 \\
\hline 14 & 6.24 & 6.17 & 0.07 \\
\hline \multicolumn{4}{|c|}{ RATO 6} \\
\hline No & AREAF $/ \mathrm{mm}^{\wedge} \mathbf{2}$ & AREA $/ \mathrm{mm}^{\wedge} 2$ & AREAINT/mm^2 \\
\hline 1 & 37.38 & 23.86 & 13.52 \\
\hline 2 & 41.15 & 29.83 & 11.32 \\
\hline 3 & 43.72 & 31.96 & 11.76 \\
\hline 4 & 43.84 & 33.31 & 10.53 \\
\hline 5 & 40.54 & 29.41 & 11.13 \\
\hline 6 & 38.07 & 29.78 & 8.29 \\
\hline 7 & 36.86 & 28.21 & 8.66 \\
\hline 8 & 33.71 & 24.43 & 9.27 \\
\hline 9 & 31.13 & 24.05 & 7.08 \\
\hline 10 & 28.54 & 21.15 & 7.39 \\
\hline 11 & 23.25 & 17.56 & 5.70 \\
\hline 12 & 20.69 & 15.64 & 5.05 \\
\hline 13 & 16.18 & 13.28 & 2.90 \\
\hline 14 & 12.36 & 10.40 & 1.96 \\
\hline 15 & 6.22 & 5.82 & 0.40 \\
\hline
\end{tabular}

GRUPO CONTROLE MAIS ESTRESSE (SALINA MAIS ESTRESSE DE 3 HORAS)

RATO 1

\begin{tabular}{llll}
\hline No & AREAF $/ \mathrm{mm}^{\wedge} 2$ & AREA $/ \mathrm{mm}^{\wedge} 2$ & AREAINT/mm^2 \\
\hline 1 & 36.29 & 24.75 & 11.54 \\
\hline 2 & 39.28 & 28.20 & 11.08 \\
\hline 3 & 43.62 & 31.04 & 12.58 \\
\hline
\end{tabular}




\begin{tabular}{llll}
\hline 4 & 41.88 & 30.30 & 11.57 \\
\hline 5 & 44.17 & 31.90 & 12.28 \\
\hline 6 & 38.58 & 27.31 & 11.27 \\
\hline 7 & 39.19 & 27.13 & 12.07 \\
\hline 8 & 38.11 & 25.16 & 12.95 \\
\hline 9 & 34.74 & 23.32 & 11.42 \\
\hline 10 & 31.34 & 21.14 & 10.20 \\
\hline 11 & 24.20 & 15.17 & 9.03 \\
\hline 12 & 27.82 & 19.53 & 8.29 \\
\hline 13 & 25.31 & 18.40 & 6.91 \\
\hline 14 & 23.17 & 17.09 & 6.08 \\
\hline 15 & 18.76 & 14.09 & 4.67 \\
\hline
\end{tabular}

\begin{tabular}{|c|c|c|c|}
\hline \multicolumn{4}{|c|}{ RATO 2} \\
\hline No & AREAF/mm^2 & AREA $/ \mathrm{mm}^{\wedge} 2$ & AREAINT/mm^2 \\
\hline 1 & 33.97 & 23.89 & 10.08 \\
\hline 2 & 35.46 & 25.66 & 9.80 \\
\hline 3 & 36.52 & 27.46 & 9.05 \\
\hline 4 & 38.91 & 29.89 & 9.02 \\
\hline 5 & 39.75 & 29.39 & 10.36 \\
\hline 6 & 37.83 & 28.79 & 9.04 \\
\hline 7 & 39.12 & 28.50 & 10.62 \\
\hline 8 & 40.12 & 29.50 & 10.61 \\
\hline 9 & 37.91 & 26.83 & 11.08 \\
\hline 10 & 34.73 & 26.12 & 8.61 \\
\hline 11 & 31.84 & 24.81 & 7.04 \\
\hline $1 ?$ & 30.19 & 23.09 & 7.11 \\
\hline 13 & 28.91 & 22.38 & 6.53 \\
\hline 14 & 25.42 & 20.09 & 5.33 \\
\hline 15 & 20.99 & 17.20 & 3.79 \\
\hline \multicolumn{4}{|c|}{ RATO 3 } \\
\hline No & AREAF $/ \mathrm{mm}^{\wedge} 2$ & AREA $/ \mathrm{mm}^{\wedge} \mathbf{2}$ & AREA $/ \mathrm{mm}^{\wedge} \mathbf{2}$ \\
\hline 1 & 37.20 & 22.50 & 14,7 \\
\hline 2 & 37.94 & 26.58 & 11,36 \\
\hline 3 & 42.81 & 30.91 & 11,9 \\
\hline 4 & 38.48 & 27.29 & 11,9 \\
\hline 5 & 40.64 & 29.49 & 11,15 \\
\hline 6 & 41.58 & 31.98 & 9,6 \\
\hline 7 & 41.19 & 32.60 & 8,59 \\
\hline 8 & 36.76 & 28.29 & 8,47 \\
\hline 9 & 35.58 & 29.14 & 6,44 \\
\hline 10 & 34.69 & 27.43 & 7,26 \\
\hline
\end{tabular}




\begin{tabular}{|c|c|c|c|}
\hline 11 & 33.40 & 27.28 & 6,12 \\
\hline 12 & 34.19 & 27.68 & 6,51 \\
\hline 13 & 30.25 & 25.09 & 5,16 \\
\hline 14 & 26.67 & 22.06 & 4,61 \\
\hline 15 & 23.20 & 19.32 & 3,88 \\
\hline 16 & 19.63 & 16.74 & 2,89 \\
\hline \multicolumn{4}{|c|}{ RATO 4} \\
\hline No & AREAF $/ \mathrm{mm}^{\wedge} \mathbf{2}$ & AREA/mm^2 & AREA $/ \mathrm{mm}^{\wedge} 2$ \\
\hline 1 & 33.46 & 27.09 & 6,37 \\
\hline 2 & 39.81 & 32.13 & 7,68 \\
\hline 3 & 40.38 & 33.83 & 6,55 \\
\hline 4 & 41.68 & 33.69 & 7,99 \\
\hline 5 & 42.15 & 35.26 & 6,89 \\
\hline 6 & 41.06 & 33.80 & 7,26 \\
\hline 7 & 37.33 & 30.88 & 6,45 \\
\hline 8 & 34.44 & 27.51 & 6,93 \\
\hline 9 & 30.41 & 25.54 & 5,17 \\
\hline 10 & 27.38 & 22.92 & 4,46 \\
\hline 11 & 32.48 & 27.08 & 5,4 \\
\hline 12 & 27.99 & 22.68 & 5,31 \\
\hline 13 & 21.59 & 17.89 & 3,71 \\
\hline 14 & 18.49 & 16.06 & 2,43 \\
\hline 1.5 & 16.30 & 14.34 & 1,96 \\
\hline \multicolumn{4}{|c|}{ RATO 5} \\
\hline No & AREAF $/ \mathrm{mm}^{\wedge} \mathbf{2}$ & AREA $/ \mathrm{mm}^{\wedge} 2$ & AREA $/ \mathrm{mm}^{\wedge} 2$ \\
\hline 1 & 29.05 & 19.47 & 9,58 \\
\hline 2 & 39.86 & 28.69 & 11,17 \\
\hline 3 & 41.80 & 30.63 & 11,17 \\
\hline 4 & 42.83 & 29.22 & 13,61 \\
\hline 5 & 43.94 & 31.64 & 12,3 \\
\hline 6 & 42.90 & 30.78 & 12,12 \\
\hline 7 & 45.77 & 33.66 & 12,11 \\
\hline 8 & 43.97 & 28.94 & 15,03 \\
\hline 9 & 40.35 & 26.41 & 13,94 \\
\hline 10 & 40.34 & 27.02 & 13,32 \\
\hline 11 & 38.51 & 25.63 & 12,88 \\
\hline 12 & 35.45 & 23.55 & 11,9 \\
\hline 13 & 34.50 & 22.82 & 11,68 \\
\hline 14 & 30.60 & 20.14 & 10,46 \\
\hline 15 & 28.85 & .20 .50 & 8,35 \\
\hline
\end{tabular}




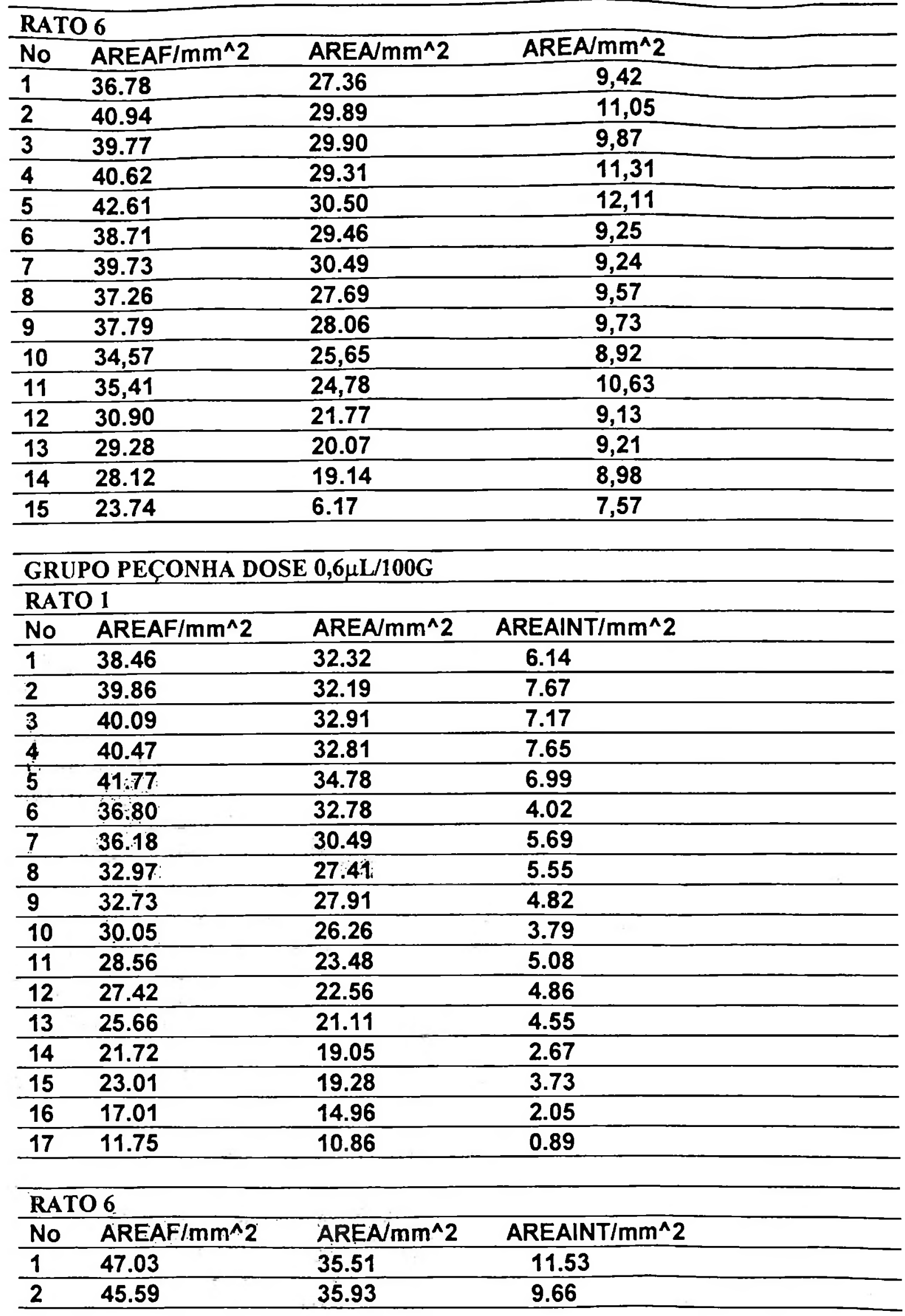




\begin{tabular}{llll}
\hline 3 & 49.02 & 39.05 & 9.97 \\
\hline 4 & 45.69 & 36.62 & 9.08 \\
\hline 5 & 44.14 & 35.50 & 8.64 \\
\hline 6 & 42.24 & 32.69 & 9.54 \\
\hline 7 & 42.05 & 32.72 & 9.33 \\
\hline 8 & 37.38 & 28.77 & 8.61 \\
\hline 9 & 37.44 & 27.26 & 10.18 \\
\hline 10 & 31.76 & 24.16 & 7.60 \\
\hline 11 & 33.29 & 25.25 & 8.04 \\
\hline 12 & 27.06 & 21.32 & 5.74 \\
\hline 13 & 25.73 & 21.18 & 4.55 \\
\hline 14 & 19.17 & 17.49 & 1.68 \\
\hline 15 & 21.53 & 17.70 & 3.83 \\
\hline 16 & 15.34 & 12.78 & 2.56 \\
\hline 17 & 9.34 & 7.86 & 1.48 \\
\hline
\end{tabular}

\begin{tabular}{llll}
\hline \multicolumn{2}{l}{ RATO12 } & & \\
\hline No & AREAF/mm² & AREA $/ \mathrm{mm}^{\wedge} 2$ & AREAINT/mm^2 \\
\hline 1 & 45.26 & 34.59 & 10.67 \\
\hline 2 & 47.97 & 37.33 & 10.64 \\
\hline 3 & 48.03 & 36.54 & 11.50 \\
\hline 4 & 50.66 & 38.82 & 11.84 \\
\hline 5 & 50.78 & 39.12 & 11.66 \\
\hline 6 & 48.43 & 36.29 & 12.13 \\
\hline 7 & 45.65 & 34.30 & 11.35 \\
\hline 8 & 45.24 & 33.45 & 11.79 \\
\hline 9 & 40.29 & 30.02 & 10.27 \\
\hline 10 & 40.14 & 30.38 & 9.77 \\
\hline 11 & 34.04 & 25.24 & 8.79 \\
\hline 12 & 30.64 & 22.84 & 7.80 \\
\hline 13 & 25.47 & 19.81 & 5.66 \\
\hline 14 & 25.72 & 19.74 & 5.98 \\
\hline 15 & 24.86 & 18.86 & 6.00 \\
\hline 16 & 16.83 & 15.65 & 1.18 \\
\hline 17 & 8.76 & 8.76 & 0.00 \\
\hline
\end{tabular}

\begin{tabular}{|c|c|}
\hline ÁRE & DE LESÃO DO RATO 12 \\
\hline No & AREA $/ \mathrm{mm}^{\wedge} 2$ \\
\hline 1 & 0.45 \\
\hline
\end{tabular}

\begin{tabular}{|c|c|c|c|}
\hline & & & \\
\hline No & AREAF $/ \mathrm{mm}^{\wedge} \mathbf{2}$ & & AREA $/ \mathrm{mm}^{\wedge} 2$ AREAIN $/ \mathrm{mm}^{\wedge} 2$ \\
\hline 1 & 43.66 & 29.88 & 13.77 \\
\hline
\end{tabular}




\begin{tabular}{llll}
\hline 2 & 43.96 & 30.02 & 13.94 \\
\hline 3 & 47.07 & 31.71 & 15.36 \\
\hline 4 & 46.61 & 31.02 & 15.59 \\
\hline 5 & 44.99 & 30.38 & 14.60 \\
\hline 6 & 48.68 & 33.71 & 14.97 \\
\hline 7 & 48.35 & 31.31 & 17.04 \\
\hline 8 & 47.04 & 29.92 & 17.12 \\
\hline 9 & 46.48 & 28.64 & 17.84 \\
\hline 10 & 42.67 & 26.79 & 15.87 \\
\hline 11 & 37.11 & 25.29 & 11.82 \\
\hline 12 & 36.85 & 25.92 & 10.93 \\
\hline 13 & 30.78 & 21.18 & 9.59 \\
\hline 14 & 26.28 & 19.96 & 6.32 \\
\hline 15 & 27.02 & 20.33 & 6.69 \\
\hline 16 & 18.82 & 12.43 & 6.40 \\
\hline 17 & 9.75 & 9.25 & 0.50 \\
\hline
\end{tabular}

\begin{tabular}{|c|c|c|c|}
\hline \multicolumn{4}{|c|}{ RATO 20} \\
\hline No & AREAF $/ \mathrm{mm}^{\wedge} \mathbf{2}$ & AREA $/ \mathrm{mm}^{\wedge} \mathbf{2}$ & AREAINT/mm^2 \\
\hline 1 & 46.33 & 34.16 & 12.17 \\
\hline 2 & 43.65 & 33.13 & 10.52 \\
\hline 3 & 43.35 & 34.72 & 8.63 \\
\hline 4 & 44.62 & 36.54 & 8.07 \\
\hline 5 & 43.69 & 35.67 & 8.02 \\
\hline 6 & 39.59 & 35.52 & 4.06 \\
\hline 7 & 42.85 & 37.34 & 5.51 \\
\hline 8 & 41.31 & 33.73 & 7.59 \\
\hline 9 & 40.13 & 33.53 & 6.60 \\
\hline 10 & 39.86 & 33.55 & 6.32 \\
\hline 11 & 35.73 & 30.01 & 5.72 \\
\hline 12 & 32.24 & 27.12 & 5.12 \\
\hline 13 & 31.77 & 26.39 & 5.38 \\
\hline 14 & 27.77 & 22.24 & 5.53 \\
\hline 15 & 26.69 & 21.66 & 5.03 \\
\hline 16 & 21.32 & 17.68 & 3.64 \\
\hline 17 & 15.42 & 13.59 & 1.83 \\
\hline 18 & 7.56 & 7.41 & 0.14 \\
\hline \multicolumn{4}{|c|}{ ÁREA DE LESÃO DO RATO 20} \\
\hline No & AREA $/ \mathrm{mm}^{\wedge} \mathbf{2}$ & & \\
\hline 1 & 0.19 & & \\
\hline
\end{tabular}




\begin{tabular}{|c|c|c|c|}
\hline No & AREAF/mm^2 & AREA $/ \mathrm{mm}^{\wedge} \mathbf{2}$ & AREAINT/ $\mathrm{mm}^{\wedge} 2$ \\
\hline 1 & 41.52 & 29.46 & 12.06 \\
\hline 2 & 42.52 & 29.82 & 12.69 \\
\hline 3 & 44.74 & 33.42 & 11.32 \\
\hline 4 & 43.29 & 31.98 & 11.31 \\
\hline 5 & 45.28 & 34.23 & 11.05 \\
\hline 6 & 44.85 & 33.50 & 11.35 \\
\hline 7 & 42.59 & 32.16 & 10.43 \\
\hline 8 & 39.15 & 29.18 & 9.97 \\
\hline 9 & 42.89 & 31.88 & 11.02 \\
\hline 10 & 41.09 & 30.78 & 10.31 \\
\hline 11 & 40.77 & 29.81 & 10.96 \\
\hline 12 & 38.24 & 27.61 & 10.63 \\
\hline 13 & 32.91 & 24.09 & 8.81 \\
\hline 14 & 28.70 & 21.14 & 7.56 \\
\hline 15 & 27.53 & 20.71 & 6.82 \\
\hline 16 & 26.72 & 20.50 & 6.23 \\
\hline 17 & 20.97 & 17.96 & 3.01 \\
\hline 18 & 13.74 & 12.72 & 1.02 \\
\hline
\end{tabular}

GRUPO PECCONHA DOSE $0,8 \mu \mathrm{L} / 100 \mathrm{G}$

RATO11

\begin{tabular}{llll}
\hline No & AREAF $/ \mathrm{mm}^{\wedge} 2$ & AREA $/ \mathrm{mm}^{\wedge} 2$ & AREAINT/mm^2 \\
\hline 1 & 35.55 & 25.69 & 9.87 \\
\hline 2 & 38.54 & 28.48 & 10.06 \\
\hline 3 & 40.81 & 29.69 & 11.12 \\
\hline 4 & 40.84 & 29.88 & 10.96 \\
\hline 5 & 42.02 & 30.54 & 11.48 \\
\hline 6 & 41.51 & 29.96 & 11.56 \\
\hline 7 & 40.60 & 27.99 & 12.60 \\
\hline 8 & 37.02 & 26.78 & 10.24 \\
\hline 9 & 36.24 & 27.45 & 8.79 \\
\hline 10 & 32.31 & 23.87 & 8.45 \\
\hline 11 & 28.62 & 21.20 & 7.43 \\
\hline 12 & 25.36 & 19.27 & 6.09 \\
\hline 13 & 21.30 & 16.16 & 5.15 \\
\hline 14 & 17.75 & 14.59 & 3.16 \\
\hline 15 & 11.67 & 10.21 & 1.47 \\
\hline 16 & 4.69 & 4.65 & 0.04 \\
\hline
\end{tabular}

\begin{tabular}{l}
\hline ÁREA DA LESÃO DO RATO 11 \\
\hline No AREA $/ \mathrm{mm}^{\wedge} 2$ \\
\hline $1 \quad 0.30$ \\
\hline
\end{tabular}


20.46

RATO 3

\begin{tabular}{|c|c|c|c|}
\hline No & AREAF $/ \mathrm{mm}^{\wedge} \mathbf{2}$ & AREA $/ \mathrm{mm}^{\wedge} \mathbf{2}$ & AREAINT/mm^2 \\
\hline 1 & 44.09 & 34.89 & 9.19 \\
\hline 2 & 46.64 & 37.38 & 9.25 \\
\hline 3 & 48.22 & 39.18 & 9.04 \\
\hline 4 & 48.38 & 39.59 & 8.80 \\
\hline 5 & 47.04 & 39.47 & 7.57 \\
\hline 6 & 45.43 & 37.66 & 7.77 \\
\hline 7 & 45.11 & 38.12 & 6.99 \\
\hline 8 & 42.21 & 34.87 & 7.34 \\
\hline 9 & 39.60 & 34.16 & 5.44 \\
\hline 10 & 38.65 & 33.61 & 5.04 \\
\hline 11 & 35.62 & 31.72 & 3.89 \\
\hline 12 & 27.68 & 24.83 & 2.85 \\
\hline 13 & 23.89 & 20.96 & 2.93 \\
\hline 14 & 19.41 & 17.14 & 2.28 \\
\hline 15 & 13.68 & 12.06 & 1.62 \\
\hline
\end{tabular}

ÁREA DE LESÃO DO RATO 3

No AREA $/ \mathrm{mm}^{\wedge} \mathbf{2}$

$\begin{array}{ll}1 & 0.07\end{array}$

$2 \quad 0.22$

3.18

\begin{tabular}{ll}
\hline 4 & 2.95 \\
\hline 5 & 2.21 \\
\hline
\end{tabular}

RATO 7

\begin{tabular}{llll}
\hline No & AREAF $/ \mathrm{mm}^{\wedge} 2$ & AREA $/ \mathrm{mm}^{\wedge} 2$ & AREAINT/mm^2 \\
\hline 1 & 43.08 & 31.10 & 11.98 \\
\hline 2 & 45.01 & 32.66 & 12.35 \\
\hline 3 & 45.98 & 33.74 & 12.24 \\
\hline 4 & 44.44 & 31.22 & 13.22 \\
\hline 5 & 47.06 & 33.86 & 13.20 \\
\hline 6 & 44.12 & 31.60 & 12.52 \\
\hline 7 & 39.07 & 28.16 & 10.92 \\
\hline 8 & 36.52 & 26.56 & 9.96 \\
\hline 9 & 29.70 & 22.21 & 7.49 \\
\hline 10 & 25.83 & 19.02 & 6.81 \\
\hline 11 & 20.59 & 16.75 & 3.84 \\
\hline 12 & 14.59 & 13.62 & 0.97 \\
\hline 13 & 8.39 & 8.31 & 0.07 \\
\hline
\end{tabular}




\begin{tabular}{|c|c|c|c|}
\hline \multicolumn{4}{|c|}{ ÁREA DA LESÃO DO RATO 7} \\
\hline No & AREA $/ \mathrm{mm}^{\wedge} 2$ & & \\
\hline 1 & 0.17 & & \\
\hline 2 & 0.09 & & \\
\hline 3 & 0.67 & & \\
\hline 4 & 2.22 & & \\
\hline 5 & 1.12 & & \\
\hline \multicolumn{4}{|c|}{ RATO 6 } \\
\hline No & AREAF/mm^2 & AREA $/ \mathrm{mm}^{\wedge} 2$ & AREAINT/mm^2 \\
\hline 1 & 36.54 & 26.72 & 9.82 \\
\hline 2 & 44.94 & 33.09 & 11.84 \\
\hline 3 & 45.67 & 34.81 & 10.86 \\
\hline 4 & 46.87 & 34.59 & 12.28 \\
\hline 5 & 40.75 & 31.11 & 9.64 \\
\hline 6 & 41.50 & 31.63 & 9.87 \\
\hline 7 & 40.89 & 30.53 & 10.36 \\
\hline 8 & 37.16 & 28.73 & 8.43 \\
\hline 9 & 33.13 & 24.39 & 8.74 \\
\hline 10 & 30.95 & 23.40 & 7.55 \\
\hline 11 & 28.03 & 22.44 & 5.59 \\
\hline 12 & 23.52 & 19.18 & 4.35 \\
\hline 13 & 20.37 & 16.73 & 3.64 \\
\hline 14 & 16.30 & 14.62 & 1.68 \\
\hline 15 & 10,31 & 10.11 & 0.19 \\
\hline 16 & $4: 82$ & 4.82 & 0.00 \\
\hline \multicolumn{4}{|c|}{ AREA DA LESÃO DO RATO 6} \\
\hline No & AREA $/ \mathrm{mm}^{\wedge} 2$ & & \\
\hline 1 & 0.19 & & \\
\hline 2 & 0.04 & & \\
\hline 3 & 0.06 & & \\
\hline 4 & 0.05 & & \\
\hline 5 & 0.04 & & \\
\hline \multicolumn{4}{|c|}{ RATO 5A } \\
\hline No & AREAF/mm^2 & AREA/mm^2 & AREAINT/mm^2 \\
\hline 1 & 46.34 & 35.35 & 11.00 \\
\hline 2 & 49.77 & 39.64 & 10.13 \\
\hline 3 & 52.34 & 38.88 & 13.46 \\
\hline 4 & 53.24 & 38.13 & 15.11 \\
\hline 5 & 53.11 & 37.43 & 15.69 \\
\hline
\end{tabular}




\begin{tabular}{|c|c|c|c|}
\hline 6 & 50.10 & 35.13 & 14.97 \\
\hline 7 & 46.88 & 31.55 & 15.33 \\
\hline 8 & 45.01 & 30.72 & 14.30 \\
\hline 9 & 43.43 & 29.06 & 14.37 \\
\hline 10 & 35.84 & 24.40 & 11.43 \\
\hline 11 & 32.16 & 23.36 & 8.80 \\
\hline 12 & 23.29 & 21.40 & 1.89 \\
\hline 13 & 16.53 & 14.05 & 2.47 \\
\hline 14 & 8.23 & 7.60 & 0.63 \\
\hline \multicolumn{4}{|c|}{ RATO 10} \\
\hline No & AREAF $/ \mathrm{mm}^{\wedge} \mathbf{2}$ & AREA/mm² & AREAINT/mm^2 \\
\hline 1 & 43.32 & 35.36 & 7.97 \\
\hline 2 & 48.78 & 37.56 & 11.22 \\
\hline 3 & 50.00 & 37.70 & 12.30 \\
\hline 4 & 50.85 & 37.67 & 13.18 \\
\hline 5 & 50.81 & 38.32 & 12.49 \\
\hline 6 & 48.43 & 34.43 & 13.99 \\
\hline 7 & 41.48 & 32.57 & 8.90 \\
\hline 8 & 38.74 & $31 . \overline{30}$ & 7.44 \\
\hline 9 & 36.37 & 29.71 & 6.66 \\
\hline 10 & 30.27 & 25.11 & 5.16 \\
\hline 11 & 24.94 & 20.36 & 4.58 \\
\hline 12 & 17.48 & 14.36 & 3.12 \\
\hline 13 & 11.12 & 9.62 & 1.51 \\
\hline 14 & 4.08 & 4.07 & 0.00 \\
\hline \multicolumn{4}{|c|}{ RATO 15} \\
\hline No & AREAF $/ \mathrm{mm}^{\wedge} 2$ & AREA/mm^2 & AREAINT/mm^2 \\
\hline 1 & 35.64 & 28.66 & 6.97 \\
\hline 2 & 44.01 & 36.13 & 7.89 \\
\hline 3 & 44.16 & 36.73 & 7.43 \\
\hline 4 & 45.48 & 38.21 & 7.27 \\
\hline 5 & 45.25 & 35.70 & 9.56 \\
\hline 6 & 42.57 & 33.61 & 8.96 \\
\hline 7 & 41.43 & 32.48 & 8.95 \\
\hline 8 & 37.85 & 30.18 & 7.67 \\
\hline 9 & 34.13 & 26.28 & 7.85 \\
\hline 10 & 28.77 & 22.90 & 5.87 \\
\hline 11 & 24.35 & 19.92 & 4.43 \\
\hline 12 & 19.30 & 17.76 & 1.54 \\
\hline 13 & 13.90 & 13.80 & 0.10 \\
\hline 14 & 6.68 & 6.68 & 0.00 \\
\hline
\end{tabular}




\begin{tabular}{|c|c|c|c|}
\hline \multicolumn{4}{|c|}{ RATO 16} \\
\hline No & AREAF/m的 2 & AREA $/ \mathrm{mm}^{\wedge} \mathbf{2}$ & AREAINT/mm^2 \\
\hline 1 & 41.47 & 29.09 & 12.38 \\
\hline 2 & 47.54 & 34.19 & 13.36 \\
\hline 3 & 47.72 & 35.14 & 12.57 \\
\hline 4 & 47.48 & 33.62 & 13.86 \\
\hline 5 & 46.74 & 34.12 & 12.61 \\
\hline 6 & 45.42 & 31.99 & 13.43 \\
\hline 7 & 42.21 & 29.83 & 12.38 \\
\hline 8 & 36.57 & 26.66 & 9.91 \\
\hline 9 & 33.70 & 24.19 & 9.52 \\
\hline 10 & 28.46 & 20.10 & 8.36 \\
\hline 11 & 23.18 & 17.73 & 5.45 \\
\hline 12 & 17.89 & 15.32 & 2.56 \\
\hline 13 & 12.10 & 10.98 & 1.12 \\
\hline 14 & 4.78 & 4.70 & 0.08 \\
\hline \multicolumn{4}{|c|}{ RATO13 } \\
\hline No & AREAF/mm^2 & AREA $/ \mathrm{mm}^{\wedge} 2$ & AREAINT/mm^2 \\
\hline 1 & 37.10 & 26.19 & 10.91 \\
\hline 2 & 39.71 & 28.18 & 11.53 \\
\hline 3 & 44.07 & 30.50 & 13.57 \\
\hline 4 & 43.30 & 29.87 & 13.44 \\
\hline 5 & 43.87 & 29.88 & 13.98 \\
\hline 6 & 42.99 & 28.55 & 14.43 \\
\hline 7 & 43,00 & 28.14 & 14.85 \\
\hline 8 & 37.95 & 25.15 & 12.80 \\
\hline 9 & 33.52 & 23.12 & 10.41 \\
\hline 10 & 30.25 & 23.05 & 7.20 \\
\hline 11 & 23.35 & 18.71 & 4.63 \\
\hline 12 & 15.52 & 12.60 & 2.93 \\
\hline 13 & 9.80 & 7.47 & 2.33 \\
\hline 14 & 6.19 & 4.39 & 1.80 \\
\hline \multicolumn{4}{|c|}{ RATO 14 } \\
\hline No & AREAF $/ \mathrm{mm}^{\wedge} \mathbf{2}$ & AREA/mm^2 & AREAINT/ $\mathrm{mm}^{\wedge} \mathbf{2}$ \\
\hline 1 & 51.07 & 30.60 & 20.47 \\
\hline 2 & 55.69 & 35.29 & 20.40 \\
\hline 3 & 57.56 & 37.61 & 19.95 \\
\hline 4 & 53.88 & 35.37 & 18.51 \\
\hline 5 & 51.39 & 35.48 & 15.91 \\
\hline 6 & 47.71 & 33.09 & 14.62 \\
\hline
\end{tabular}




\begin{tabular}{llll}
\hline 7 & 44.02 & 30.47 & 13.56 \\
\hline 8 & 37.57 & 27.28 & 10.28 \\
\hline 9 & 32.54 & 25.08 & 7.46 \\
\hline 10 & 26.87 & 21.31 & 5.55 \\
\hline 11 & 22.01 & 18.45 & 3.56 \\
\hline 12 & 18.42 & 15.66 & 2.76 \\
\hline 13 & 14.39 & 13.30 & 1.09 \\
\hline 14 & 10.90 & 10.20 & 0.71 \\
\hline 15 & 5.57 & 5.55 & 0.02 \\
\hline
\end{tabular}

\begin{tabular}{|c|c|c|c|}
\hline \multicolumn{4}{|c|}{ RATO3 } \\
\hline No & AREAF/mm^2 & AREA $/ \mathrm{mm}^{\wedge} \mathbf{2}$ & AREAINT/mm^2 \\
\hline 1 & 32.29 & 24.04 & 8.25 \\
\hline 2 & 34.55 & 27.25 & 7.30 \\
\hline 3 & 36.05 & 27.82 & 8.23 \\
\hline 4 & 34.26 & 25.58 & 8.68 \\
\hline 5 & 35.69 & 28.63 & 7.06 \\
\hline 6 & 34.11 & 26.54 & 7.57 \\
\hline 7 & 31.48 & 24.52 & 6.96 \\
\hline 8 & 29.41 & 22.81 & 6.60 \\
\hline 9 & 26.64 & 22.27 & 4.37 \\
\hline 10 & 24.64 & 19.37 & 5.28 \\
\hline 11 & 20.35 & 16.13 & 4.22 \\
\hline 12 & 17.31 & 13.53 & 3.78 \\
\hline 13 & 14.19 & 11.58 & 2.61 \\
\hline 14 & 10.67 & 9.55 & 1.11 \\
\hline 15 & 61.9 & 5.97 & 0.22 \\
\hline \multicolumn{4}{|c|}{ RATO 5B } \\
\hline No & AREAF $/ \mathrm{mm}^{\wedge} \mathbf{2}$ & AREA $/ \mathrm{mm}^{\wedge} \mathbf{2}$ & AREAINT/mm^2 \\
\hline 1 & 44.00 & 25.55 & 18.45 \\
\hline 2 & 47.32 & 26.23 & 21.08 \\
\hline 3 & 49.57 & 32.35 & 17.22 \\
\hline 4 & 48.66 & 31.86 & 16.80 \\
\hline 5 & 43.38 & 27.81 & 15.56 \\
\hline 6 & 45.29 & 30.41 & 14.88 \\
\hline 7 & 45.28 & 30.16 & 15.11 \\
\hline 8 & 40.34 & 24.16 & 16.18 \\
\hline 9 & 37.43 & 22.18 & 15.25 \\
\hline \multicolumn{4}{|c|}{ RAT013 } \\
\hline No & AREAF $/ \mathrm{mm}^{\wedge} \mathbf{2}$ & AREA/mm^ 2 & AREAINT/mm^2 \\
\hline 1 & 43.17 & 31.48 & 11.69 \\
\hline
\end{tabular}




\begin{tabular}{|c|c|c|c|}
\hline 2 & 45.16 & 33.90 & 11.26 \\
\hline 3 & 43.52 & 32.40 & 11.12 \\
\hline 4 & 42.26 & 29.42 & 12.84 \\
\hline 5 & 46.14 & 33.32 & 12.82 \\
\hline 6 & 46.06 & 32.11 & 13.95 \\
\hline 7 & 43.59 & 30.81 & 12.79 \\
\hline 8 & 40.08 & 27.68 & 12.40 \\
\hline 9 & 40.55 & 28.06 & 12.49 \\
\hline 10 & 37.51 & 25.45 & 12.06 \\
\hline 11 & 36.00 & 25.01 & 10.98 \\
\hline 12 & 29.31 & 19.59 & 9.72 \\
\hline 13 & 31.79 & 21.96 & 9.83 \\
\hline 14 & 27.37 & 19.01 & 8.36 \\
\hline 15 & 23.83 & 16.20 & 7.63 \\
\hline 16 & 18.91 & 13.79 & 5.12 \\
\hline 17 & 19.22 & 15.38 & 3.83 \\
\hline 18 & 14.68 & 12.60 & 2.08 \\
\hline 19 & 6.86 & 6.63 & 0.23 \\
\hline \multicolumn{4}{|c|}{ RAT05C } \\
\hline No & AREAF/mm^2 & AREA $/ \mathrm{mm}^{\wedge} 2$ & AREAINT/mm^2 \\
\hline 1 & 36.29 & 28.30 & 7.99 \\
\hline 2 & 39.15 & 30.06 & 9.09 \\
\hline 3 & 42.50 & 32.66 & 9.83 \\
\hline 4 & 44.26 & 33.63 & 10.63 \\
\hline 5 & 43.77 & 33.57 & 10.20 \\
\hline 6 & 43.37 & 32.63 & 10.73 \\
\hline 7 & 42.05 & 31.69 & 10.36 \\
\hline 8 & 40.52 & 29.46 & 11.06 \\
\hline 9 & 35.19 & 25.96 & 9.22 \\
\hline 10 & 35.63 & 26.09 & 9.55 \\
\hline 11 & 34.25 & 23.48 & 10.77 \\
\hline 12 & 27.09 & 19.98 & 7.11 \\
\hline 13 & 25.37 & 17.51 & 7.86 \\
\hline 14 & 23.27 & 15.85 & 7.42 \\
\hline 15 & 17.08 & 12.57 & 4.51 \\
\hline 16 & 11.94 & 8.78 & 3.16 \\
\hline \multicolumn{4}{|c|}{ RATO 6} \\
\hline No & AREAF $/ \mathrm{mm}^{\wedge} \mathbf{2}$ & AREA/mm^2 & AREAINT/mm^2 \\
\hline 1 & 44.38 & 32.97 & 11.40 \\
\hline 2 & 46.37 & 31.96 & 14.40 \\
\hline 3 & 46.15 & 34.05 & 12.10 \\
\hline
\end{tabular}




\begin{tabular}{llll}
\hline 4 & 40.82 & 30.37 & 10.45 \\
\hline 5 & 40.89 & 30.31 & 10.59 \\
\hline 6 & 40.10 & 28.84 & 11.26 \\
\hline 7 & 36.22 & 26.45 & 9.77 \\
\hline 8 & 33.09 & 23.68 & 9.41 \\
\hline 9 & 30.80 & 22.70 & 8.09 \\
\hline 10 & 27.39 & 21.23 & 6.16 \\
\hline 11 & 25.16 & 20.45 & 4.72 \\
\hline 12 & 20.18 & 16.33 & 3.85 \\
\hline 13 & 16.06 & 13.94 & 2.12 \\
\hline 14 & 10.28 & 9.93 & 0.36 \\
\hline 15 & 4.63 & 4.62 & 0.00 \\
\hline
\end{tabular}

ÁREA DA LESĀO DO RATO 6

No AREA $/ \mathrm{mm}^{\wedge} 2$

\begin{tabular}{ll}
\hline 1 & 0.16 \\
\hline 2 & 0.09 \\
\hline 3 & 0.39
\end{tabular}

\begin{tabular}{|c|c|c|c|}
\hline \multicolumn{4}{|c|}{ RATO 5D } \\
\hline No & AREAF $/ \mathrm{mm}^{\wedge} 2$ & AREA/m $\mathrm{m}^{\wedge} 2$ & AREAINT/mm^2 \\
\hline 1 & 29.28 & 23.51 & 5.76 \\
\hline 2 & 39.36 & 28.13 & 11.24 \\
\hline 3 & 40.06 & 29.86 & 10.20 \\
\hline 4 & 44.12 & 31.35 & 12.77 \\
\hline 5 & 43.42 & 32.39 & 11.03 \\
\hline 6 & 43.65 & 32.81 & 10.84 \\
\hline 7 & 41.87 & 29.72 & 12.15 \\
\hline 8 & 39.87 & 27.00 & 12.86 \\
\hline 9 & 37.41 & 26.86 & 10.54 \\
\hline 10 & 36.03 & 25.73 & 10.30 \\
\hline 11 & 33.91 & 23.42 & 10.49 \\
\hline 12 & 29.75 & 21.25 & 8.50 \\
\hline 13 & 26.01 & 18.16 & 7.86 \\
\hline 14 & 23.29 & 16.61 & 6.68 \\
\hline 15 & 16.65 & 12.37 & 4.28 \\
\hline 16 & 11.83 & 8.39 & 3.43 \\
\hline \multicolumn{4}{|c|}{ RATO 5E } \\
\hline No & AREAF $/ \mathrm{mm}^{\wedge} \mathbf{2}$ & AREA/mm^2 & AREAINT/mm^2 \\
\hline 1 & 49.71 & 38.01 & 11.70 \\
\hline 2 & 52.06 & 36.31 & 15.75 \\
\hline 3 & 52.94 & 36.30 & 16.64 \\
\hline
\end{tabular}




\begin{tabular}{llll}
\hline 4 & 52.48 & 35.94 & 16.54 \\
\hline 5 & 43.98 & 33.59 & 10.39 \\
\hline 6 & 44.75 & 29.56 & 15.19 \\
\hline 7 & 45.21 & 29.19 & 16.03 \\
\hline 8 & 43.16 & 28.95 & 14.21 \\
\hline 9 & 36.21 & 24.43 & 11,78 \\
\hline 10 & 31.06 & 21.74 & 9.33 \\
\hline 11 & 19.41 & 16.73 & 2.69 \\
\hline 12 & 16.61 & 13.80 & 2.82 \\
\hline 13 & 8.19 & 6.99 & 1.20 \\
\hline
\end{tabular}

GRUPO ESTRESSE DE 3 HORAS MAIS PEÇONHA DOSE 0,6 $\mu \mathrm{L} / 100 \mathrm{G}$

\begin{tabular}{|c|c|c|c|}
\hline \multicolumn{4}{|c|}{ RATO 2} \\
\hline No & AREAF/mm^2 & AREA $/ \mathrm{mm}^{\wedge} \mathbf{2}$ & AREAINT/mm^2 \\
\hline 1 & 41.33 & 29.75 & 11.58 \\
\hline 2 & 42.18 & 30.37 & 11.81 \\
\hline 3 & 42.55 & 30.43 & 12.12 \\
\hline 4 & 44.86 & 30.85 & 14.01 \\
\hline 5 & 42.15 & 29.45 & 12.70 \\
\hline 6 & 39.14 & 27.13 & 12.02 \\
\hline 7 & 39.24 & 27.23 & 12.01 \\
\hline 8 & 38.58 & 26.64 & 11.95 \\
\hline 9 & 35.24 & 24.55 & 10.69 \\
\hline 10 & 30.58 & 21.76 & 8.82 \\
\hline 11 & 30.26 & 21.94 & 8.32 \\
\hline 12 & 27.16 & 20.43 & 6.73 \\
\hline 13 & 22.37 & 16.96 & 5.42 \\
\hline 14 & 17.88 & 14.77 & 3.11 \\
\hline
\end{tabular}

\begin{tabular}{ll}
\hline \multicolumn{2}{l}{ ÁREA DA LESÃO DO RATO 2} \\
\hline No & AREA/mm^2 \\
\hline 1 & 1.04 \\
\hline 2 & 1.19 \\
\hline 3 & 1.83 \\
\hline
\end{tabular}

\begin{tabular}{|c|c|c|c|}
\hline \multicolumn{4}{|c|}{ RATO 3} \\
\hline No & AREAF $/ \mathrm{mm}^{\wedge} 2$ & AREA/mm^^2 & AREAINT/mm^^ \\
\hline 1 & 32.90 & 25.82 & 7.08 \\
\hline 2 & 37.90 & 32.45 & 5.45 \\
\hline 3 & 37.67 & 33.04 & 4.63 \\
\hline 4 & 37.36 & 32.18 & 5.19 \\
\hline 5 & 34.85 & 29.42 & 5.43 \\
\hline 6 & 34.12 & 29.42 & 4.70 \\
\hline
\end{tabular}




\begin{tabular}{llll}
\hline 7 & 34.55 & 30.85 & 3.70 \\
\hline 8 & 33.53 & 29.53 & 4.00 \\
\hline 9 & 30.57 & 27.32 & 3.25 \\
\hline 10 & 29.83 & 27.33 & 2.50 \\
\hline 11 & 26.20 & 24.19 & 2.01 \\
\hline 12 & 23.40 & 21.53 & 1.86 \\
\hline 13 & 18.05 & 16.78 & 1.27 \\
\hline 14 & 12.66 & 12.19 & 0.47 \\
\hline 15 & 8.52 & 8.49 & 0.03 \\
\hline
\end{tabular}

\begin{tabular}{|c|c|c|c|}
\hline \multicolumn{4}{|c|}{ ÁREA DA LESÃO DO RATO 3} \\
\hline No & AREA $/ \mathrm{mm}^{\wedge} \mathbf{2}$ & & \\
\hline 1 & 3.33 & & \\
\hline 2 & 2.40 & & \\
\hline 3 & 2.18 & & \\
\hline 4 & 0.51 & & \\
\hline \multicolumn{4}{|c|}{ RATO 1} \\
\hline No & AREAF/mm^2 & AREA $/ \mathrm{mm}^{\wedge} 2$ & AREAINT/mm^2 \\
\hline 1 & 37.96 & 30.45 & 7.51 \\
\hline 2 & 39.50 & 32.68 & 6.82 \\
\hline 3 & 39.61 & 31.71 & 7.89 \\
\hline 4 & 40.97 & 31.34 & 9.63 \\
\hline 5 & 41.58 & 31.09 & 10.49 \\
\hline 6 & 39.33 & 29.37 & 9.96 \\
\hline 7 & 39.61 & 28.34 & 11.27 \\
\hline 8 & 36.23 & 25.76 & 10.47 \\
\hline 9 & 35.02 & 24.72 & 10.30 \\
\hline 10 & 36.09 & 25.03 & 11.06 \\
\hline 11 & 29.78 & 21.66 & 8.12 \\
\hline 12 & 29.87 & 22.51 & 7.36 \\
\hline 13 & 24.53 & 20.63 & 3.90 \\
\hline 14 & 16.08 & 14.24 & 1.84 \\
\hline 15 & 8.37 & 7.38 & 0.99 \\
\hline \multicolumn{4}{|c|}{ RATO 5} \\
\hline No & AREAF $/ \mathrm{mm}^{\wedge} \mathbf{2}$ & AREA/mm^2 & AREAINT/mm^2 \\
\hline 1 & 43.19 & 31.44 & 11.75 \\
\hline 2 & 45.51 & 34.04 & 11.47 \\
\hline 3 & 49.05 & 36.23 & 12.82 \\
\hline 4 & 48.58 & 35.93 & 12.65 \\
\hline 5 & 49.90 & 35.82 & 14.08 \\
\hline 6 & 48.20 & 35.33 & 12.87 \\
\hline
\end{tabular}




\begin{tabular}{llll}
\hline 7 & 49.63 & 36.45 & 13.18 \\
\hline 8 & 46.51 & 34.55 & 11.97 \\
\hline 9 & 41.72 & 31.01 & 10.71 \\
\hline 10 & 40.82 & 29.70 & 11.12 \\
\hline 11 & 35.98 & 26.76 & 9.22 \\
\hline 12 & 33.78 & 25.72 & 8.06 \\
\hline 13 & 29.27 & 22.75 & 6.53 \\
\hline 14 & 23.04 & 19.01 & 4.03 \\
\hline 15 & 20.20 & 17.82 & 2.37 \\
\hline 16 & 17.75 & 15.35 & 2.39 \\
\hline 17 & 14.04 & 12.47 & 1.58 \\
\hline 18 & 10.51 & 10.18 & 0.33 \\
\hline
\end{tabular}

\begin{tabular}{llll}
\hline \multicolumn{1}{l}{ RATO 15} & & \\
\hline No & AREAF/mm^2 & AREA $/ \mathrm{mm}^{\wedge} 2$ & AREAINT/mm^2 \\
\hline 1 & 42.49 & 34.64 & 7.84 \\
\hline 2 & 43.16 & 34.02 & 9.13 \\
\hline 3 & 43.43 & 34.23 & 9.21 \\
\hline 4 & 41.92 & 32.55 & 9.37 \\
\hline 5 & 42.45 & 31.67 & 10.78 \\
\hline 6 & 41.26 & 31.96 & 9.30 \\
\hline 7 & 39.79 & 30.61 & 9.19 \\
\hline 8 & 38.30 & 29.06 & 9.25 \\
\hline 9 & 36.06 & 27.82 & 8.24 \\
\hline 10 & 33.93 & 26.01 & 7.91 \\
\hline 11 & 32.12 & 25.15 & 6.97 \\
\hline 12 & 29.55 & 22.23 & 7.32 \\
\hline 13 & 26.45 & 20.77 & 5.68 \\
\hline 14 & 21.76 & 17.46 & 4.29 \\
\hline 15 & 18.15 & 15.29 & 2.86 \\
\hline 16 & 13.34 & 11.09 & 2.25 \\
\hline
\end{tabular}

\begin{tabular}{llll}
\hline \multicolumn{2}{l}{ RATO 6 } & & \\
\hline No & AREAF $/ \mathrm{mm}^{\wedge} 2$ & AREA $/ \mathrm{mm}^{\wedge} 2$ & AREAINT/mm^2 \\
\hline 1 & 38.20 & 31.45 & 6.76 \\
\hline 2 & 43.26 & 35.64 & 7.63 \\
\hline 3 & 42.09 & 34.98 & 7.11 \\
\hline 4 & 41.98 & 34.42 & 7.55 \\
\hline 5 & 40.37 & 33.92 & 6.45 \\
\hline 6 & 37.70 & 32.40 & 5.30 \\
\hline 7 & 36.51 & 31.47 & 5.05 \\
\hline 8 & 34.43 & 29.97 & 4.46 \\
\hline 9 & 31.16 & 27.29 & 3.88 \\
\hline
\end{tabular}




\begin{tabular}{llll}
\hline 10 & 28.55 & 24.66 & 3.89 \\
\hline 11 & 29.11 & 25.24 & 3.87 \\
\hline 12 & 26.70 & 22.83 & 3.87 \\
\hline 13 & 24.90 & 20.87 & 4.03 \\
\hline 14 & 22.26 & 20.18 & 2.08 \\
\hline 15 & 15.29 & 11.65 & 3.64 \\
\hline 16 & 11.10 & 9.82 & 1.28 \\
\hline
\end{tabular}

GRUPO ESTRESSE DE 3 HORAS MAIS PEÇONHA NA DOSE DE $0,8 \mu \mathrm{L} / 100 \mathrm{G}$ DE PESO.

\begin{tabular}{|c|c|c|c|}
\hline \multicolumn{4}{|c|}{ RATO 2} \\
\hline No & AREAF $/ \mathrm{mm}^{\wedge} \mathrm{2}$ & AREA $/ \mathrm{mm}^{\wedge} \mathbf{2}$ & AREAINT/mm^2 \\
\hline 1 & 37.41 & 27.05 & 10.36 \\
\hline 2 & 47.31 & 36.22 & 11.09 \\
\hline 3 & 49.29 & 39.74 & 9.55 \\
\hline 4 & 50.71 & 40.58 & 10.13 \\
\hline 5 & 47.11 & 35.68 & 11.43 \\
\hline 6 & 47.42 & 36.68 & 10.74 \\
\hline 7 & 46.68 & 36.17 & 10.50 \\
\hline 8 & 45.43 & 36.40 & 9.03 \\
\hline 9 & 40.05 & 30.53 & 9.52 \\
\hline 10 & 38.63 & 29.71 & 8.92 \\
\hline 11 & 34.80 & 27.48 & 7.32 \\
\hline 12 & 30.45 & 25.60 & 4.85 \\
\hline 13 & 25.03 & 22.60 & 2.44 \\
\hline 14 & 19.80 & 18.98 & 0.82 \\
\hline 15 & 15.48 & 15.29 & 0.19 \\
\hline \multicolumn{4}{|c|}{ RATO 6} \\
\hline No & AREAF $/ \mathrm{mm}^{\wedge} \mathbf{2}$ & AREA $/ \mathrm{mm}^{\wedge} 2$ & AREAINT/mm^2 \\
\hline 1 & 38.47 & 26.75 & 11.72 \\
\hline 2 & 43.50 & 31.11 & 12.39 \\
\hline 3 & 42.30 & 29.29 & 13.01 \\
\hline 4 & 40.02 & 29.27 & 10.75 \\
\hline 5 & 40.27 & 28.62 & 11.65 \\
\hline 6 & 39.96 & 28.37 & 11.59 \\
\hline 7 & 37.54 & 25.86 & 11.67 \\
\hline 8 & 35.53 & 26.55 & 8.98 \\
\hline 9 & 31.30 & 23.09 & 8.21 \\
\hline 10 & 28.65 & 21.38 & 7.27 \\
\hline 11 & 23.32 & 17.68 & 5.64 \\
\hline 12 & 20.10 & 16.09 & 4.02 \\
\hline 13 & 6.11 & 13.76 & 2.35 \\
\hline
\end{tabular}




\begin{tabular}{llll}
\hline 14 & 10.75 & 10.17 & 0.59 \\
\hline 15 & 4.78 & 4.74 & 0.04 \\
\hline & & & \\
\hline \multicolumn{1}{|l}{ ÁREA DA LESÃO DO RATO 6 } & \\
\hline No & AREA $\mathrm{mm}^{\wedge} 2$ & \\
\hline 1 & 0.10 & \\
\hline 2 & 0.20 & \\
\hline 3 & 0.40 & \\
\hline 4 & 0.55 & \\
\hline 5 & 1.71 & \\
\hline 6 & 1.56 & \\
\hline 7 & 2.56 & \\
\hline 8 & 1.55 & \\
\hline 9 & 1.36 & \\
\hline 10 & 0.68 & \\
\hline
\end{tabular}

\begin{tabular}{|c|c|c|c|}
\hline \multicolumn{4}{|c|}{ RATO 7} \\
\hline No & AREAF $/ \mathrm{mm}^{\wedge} 2$ & AREA $/ \mathrm{mm}^{\wedge} 2$ & AREAINT/mm^2 \\
\hline 1 & 48.51 & 32.09 & 16.43 \\
\hline 2 & 54.18 & 36.03 & 18.15 \\
\hline 3 & 53.90 & 35.66 & 18.24 \\
\hline 4 & 56.43 & 38.20 & 18.24 \\
\hline 5 & 56.72 & 35.57 & 21.15 \\
\hline 6 & 51.73 & 31.78 & $\overline{19.95}$ \\
\hline 7 & 50.56 & 31.44 & 19.12 \\
\hline 8 & 45.00 & 29.20 & $\overline{15.79}$ \\
\hline 9 & 40.59 & 25.87 & $\overline{14.72}$ \\
\hline 10 & 37.00 & 23.46 & 13.54 \\
\hline 11 & 30.96 & 21.02 & $\overline{9.94}$ \\
\hline 12 & 29.33 & 21.22 & 8.11 \\
\hline 13 & 22.26 & 16.64 & 5.62 \\
\hline 14 & 18.72 & 15.91 & 2.81 \\
\hline 15 & 11.49 & 9.81 & 1.68 \\
\hline 16 & 6.75 & 6.06 & 0.69 \\
\hline
\end{tabular}

\section{RATO 8}

No AREAF $/ \mathrm{mm}^{\wedge} 2$ AREA $/ \mathrm{mm}^{\wedge} 2$ AREAINT $/ \mathrm{mm}^{\wedge} 2$

\begin{tabular}{llll}
\hline 1 & 37.81 & 27.28 & 10.53 \\
\hline 2 & 39.38 & 29.14 & 10.24 \\
\hline 3 & 41.40 & 30.69 & 10.72 \\
\hline 4 & 41.32 & 30.05 & 11.26 \\
\hline 5 & 41.24 & 28.81 & 12.43 \\
\hline 6 & 40.09 & 27.26 & 12.82 \\
\hline 7 & 39.41 & 27.42 & 11.99 \\
\hline
\end{tabular}




\begin{tabular}{llll}
\hline 8 & 36.55 & 25.11 & 11.44 \\
\hline 9 & 32.92 & 22.52 & 10.40 \\
\hline 10 & 31.66 & 22.61 & 9.06 \\
\hline 11 & 27.90 & 22.65 & 5.25 \\
\hline 12 & 20.44 & 17.40 & 3.05 \\
\hline 13 & 15.29 & 14.73 & 0.56 \\
\hline 14 & 7.66 & 7.63 & 0.03 \\
\hline 15 & 4.09 & 4.09 & 0.00 \\
\hline
\end{tabular}

RATO 13

\begin{tabular}{llll}
\hline No & AREAF $/ \mathrm{mm}^{\wedge} 2$ & AREA $/ \mathrm{mm}^{\wedge} 2$ & AREAINT/mm^2 \\
\hline 1 & 34.09 & 25.04 & 9.05 \\
\hline 2 & 45.47 & 34.32 & 11.15 \\
\hline 3 & 48.33 & 35.80 & 12.53 \\
\hline 4 & 51.59 & 37.08 & 14.51 \\
\hline 5 & 51.49 & 37.09 & 14.40 \\
\hline 6 & 48.30 & 34.53 & 13.77 \\
\hline 7 & 43.68 & 31.06 & 12.62 \\
\hline 8 & 40.50 & 30.21 & 10.30 \\
\hline 9 & 35.38 & 26.17 & 9.22 \\
\hline 10 & 32.21 & 23.73 & 8.48 \\
\hline 11 & 27.94 & 21.47 & 6.46 \\
\hline 12 & 21.26 & 17.27 & 3.99 \\
\hline 13 & 16.32 & 14.22 & 2.09 \\
\hline 14 & 11.57 & 10.40 & 1.17 \\
\hline 15 & 6.92 & 6.74 & 0.18 \\
\hline
\end{tabular}

\begin{tabular}{|c|c|c|c|}
\hline$\frac{\mathrm{RA}}{\text { No }}$ & $\frac{15}{A R E A F / m^{\wedge} 22}$ & & 2AREAINT/mm^^2 \\
\hline 1 & 38.30 & 26.21 & 12.09 \\
\hline$\underline{2}$ & 42.91 & 30.81 & 12.10 \\
\hline 3 & 47.30 & 32.66 & 14.65 \\
\hline 4 & 42.87 & 30.68 & 12.19 \\
\hline 5 & 45.00 & 30.95 & 14.04 \\
\hline 6 & 44.55 & 30.83 & 13.72 \\
\hline 7 & 41.35 & 28.40 & 12.95 \\
\hline 8 & 38.27 & 28.12 & 10.16 \\
\hline 9 & 36.42 & 26.61 & 9.81 \\
\hline 10 & 34.09 & 25.10 & 8.99 \\
\hline 11 & $3 \uparrow .36$ & 22.80 & 8.56 \\
\hline 12 & 27.91 & 20.03 & 7.88 \\
\hline 13 & 24.90 & 18.33 & 6.56 \\
\hline 14 & 20.19 & 15.71 & 4.48 \\
\hline$\overline{15}$ & $16: 3: 4$ & 13.52 & 2.80 \\
\hline
\end{tabular}


16 9.82

9.38

0.44

ÁREA DA LES̃̃O dO RATO 15

No AREA/mm^2

\begin{tabular}{ll}
$1 \quad 0.27$ \\
\hline
\end{tabular}

$2 \quad 0.23$

$3 \quad 1.00$

$4 \quad 1.85$

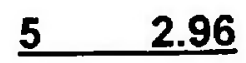

